\title{
Life Cycle Assessment for Enhanced Re-liquefaction Systems Applied to LNG Carriers; Effectiveness of Partial Re-liquefaction System
}

\author{
Taesoo Park ${ }^{1}$, Sunglack So², Byongug Jeong ${ }^{* *}$, Peilin Zhou ${ }^{1,3}$, Jae-ung Lee $^{4}$ \\ ${ }^{I}$ Department of Naval Architecture, Ocean and Marine Engineering, University of Strathclyde, 100 \\ Montrose Street, Glasgow, G4 OLZ, UK \\ ${ }^{2}$ Daewoo Ship Building \& Marine Engineering (DSME), Geo-je 53302, Republic of Korea \\ ${ }^{3}$ Harbin Institute of Technology, Weihai; No.2, West Wenhua Road, Weihai, Shandong, 264209, China \\ ${ }^{4}$ Division of Marine Information Technology, Korea Maritime and Ocean University, 727 Taejong- \\ ro, Yeongdo-gu, Busan, 49112, Republic of Korea
}

*corresponding author e-mail: byongug.jeong@strath.ac.uk

\begin{abstract}
The marine industry has been striving to seek for proper strategies to curb air emissions from global shipping activities. To support the transition to sustainable shipping, this paper was proposed to evaluate the holistic environmental benefits of the LNG partial re-liquefaction system applied to LNG carriers by comparing among five different combination/configuration of LNG re-liquefaction systems. The theory of life cycle assessment was employed with the help of a commercial software, Sphera GaBi version 2019 to quantify the magnitude of various emissions under different life stages of the proposed systems: manufacturing, installation, use and recycling. A case study was implemented with a 174,200 $\mathrm{m}^{3} \mathrm{LNG}$ carrier and the input data for the analysis was collected from true-to-life sources provided by manufacturers and ship operators. The electric consumption of the five systems were calculated by means of Aspen HYSYS software. A range from 1.23 to $1.64 \mathrm{kWh} / \mathrm{kg}$ was estimated and was used as key parameters to confirm the onboard electricity demands at the use phase of the five systems. The
\end{abstract}


results revealed that the partial re-liquefaction system had considerable effects on the reduction in emission levels across the following five impact categories: Global Warming Potential, Particulate Matter, Photochemical Ozone Creation Potential, Eutrophication Potential and Acidification Potential. An optimal option which adopted the partial re-liquefaction system was found to release $4.49 \times 10^{8} \mathrm{~kg}$ $\mathrm{CO}_{2}$ eq., $1.25 \times 10^{6} \mathrm{~kg} \mathrm{PM} 2.5$ eq., $7.16 \times 10^{6} \mathrm{~kg}$ NMVOC eq., $2.46 \times 10^{6} \mathrm{~kg} \mathrm{~N}$ eq. and $1.13 \times 10^{7} \mathrm{~kg} \mathrm{SO}_{2}$ eq. in its lifetime, which were roughly equivalent to $25 \%$ emission reductions compared to the rest of the candidates to which the partial re-liquefaction principle was not applied. Lastly, it clearly presents the effectiveness of life cycle assessment. This research, particularly, suggests that this holistic approach should not be underused for resolving innumerable maritime environmental issues that appear unsolvable with the current practices in the maritime industry.

Keywords: life cycle assessment, LNG re-liquefaction system, environmental impact, Global Warming Potential, LNG carrier 


\section{Abbreviations}

\begin{tabular}{|c|c|}
\hline AP & Acidification Potential \\
\hline BOG & Boil Off Gas \\
\hline BOR & Boil-Off Rate \\
\hline $\mathrm{C} 1$ & Methane $\left(\mathrm{CH}_{4}\right)$ \\
\hline $\mathrm{C} 2$ & Ethane $\left(\mathrm{C}_{2} \mathrm{H}_{6}\right)$ \\
\hline $\mathrm{C} 3$ & Propane $\left(\mathrm{C}_{3} \mathrm{H}_{8}\right)$ \\
\hline $\mathrm{CNG}$ & Compressed Natural Gas \\
\hline $\mathrm{CO}_{2}$ & Carbon dioxide \\
\hline Comp & Compressor \\
\hline ECAs & Emission Control Areas \\
\hline EP & Eutrophication Potential \\
\hline FLNG & Floating Liquefied Natural Gas \\
\hline FSRU & Floating Storage Regasification Unit \\
\hline GHG & Greenhouse Gas \\
\hline GTL & Gas to Liquid \\
\hline GWP & Global Warming Potential \\
\hline $\mathrm{HFO}$ & Heavy Fuel Oil \\
\hline ILCD & International reference Life Cycle Data system \\
\hline IMO & International Maritime Organization \\
\hline ISO & International Organization for Standardization \\
\hline J-T valve & Joule-Thomson valve \\
\hline LBG & Liquified Biogas \\
\hline LCA & Life Cycle Assessment \\
\hline LCI & Life Cycle Inventory analysis \\
\hline LCIA & Life Cycle Impact Assessment \\
\hline
\end{tabular}




\begin{tabular}{|c|c|}
\hline $\mathrm{LH}_{2}$ & Liquid Hydrogen \\
\hline LNG & Liquefied Natural Gas \\
\hline LPG & Liquefied Petroleum Gas \\
\hline LSFO & Low Sulphur Fuel Oil \\
\hline MCFC & Molten Carbonate Fuel Cell \\
\hline ME-GI & M-type Electronically controlled Gas Injection \\
\hline MGO & Marine Gas Oil \\
\hline MRS & Methane Refrigerant System \\
\hline $\mathrm{N}, \mathrm{N}_{2}$ & Nitrogen \\
\hline NG & Natural Gas \\
\hline NMVOC & Non-Methane Volatile Organic Compound \\
\hline $\mathrm{NO}_{\mathrm{x}}$ & Nitrogen Oxides \\
\hline PM & Particulate Matter \\
\hline POCP & Photochemical Ozone Creation Potential \\
\hline PRS & Partial Re-liquefaction System \\
\hline Ref & Refrigerant \\
\hline SFGC & Specific Fuel Gas Consumption \\
\hline SFOC & Specific Fuel Oil Consumption \\
\hline SMR & Single Mixed Refrigerant \\
\hline SOFC & Solid Oxide Fuel Cell \\
\hline $\mathrm{SO}_{\mathrm{x}}$ & Sulphur Oxides \\
\hline $\mathrm{SO}_{2}$ & Sulphur dioxide \\
\hline SVO & Straight Vegetable Oil \\
\hline
\end{tabular}




\section{Introduction}

\subsection{Background of LNG carriers and re-liquefaction systems onboard}

The global demand of LNG (Liquefied Natural Gas) has significantly increased with the emerging markets of developing countries. According to BP Energy Outlook (BP, 2019), the LNG market was expected to catch a solid upward trend over the next several decades as anticipating LNG trading volume to reach the twice level in 2016 by 2040 . Given this, the current popularity of the newbuilding of LNG carriers across the world may not be a strange phenomenon. As a good example, Qatar Petroleum, one of the world's largest LNG producers, announced a proactive plan to construct more than 60 new LNG carriers (Christopher, 2019).

LNG carriers transport the liquid form of NG (Natural Gas) at approximately $-162^{\circ} \mathrm{C}$ under the atmospheric condition (Vandebroek and Berghmans, 2012). Due to heat penetration into storage tanks during voyages, a small amount of NG continuously evaporates, which is called BOG (Boil-Off Gas). Since the gas expansion leads to escalating the tank pressure, the proper management of BOG is crucial to ensure the safety of LNG carriers against the potential risk of cargo tank rupture (Dobrota et al., 2013). There are chiefly two general options of treating the BOG onboard. The first way is to supply this gas to either steam turbines or gas-fueled engines to consume it as fuel for gaining propulsion power. The other way is to re-liquefy and return it back to the LNG cargo tanks.

The introduction of re-liquefaction plants onboard can offer several benefits to ship operators and cargo owners, compared to using it as fuel source. Greater quantity, with better quality, of LNG can be transported by reducing the BOG consumption. It can also provide flexibility in fuel selection between the BOG and oil products in response to fuel prices and LNG demand. The use of LNG re-liquefaction systems onboard LNG carriers also allows to manage their fleets in more reliable manners against diverse maneuvering conditions such as anchoring, engine stoppage and so on.

Onboard re-liquefaction systems have encountered some challenges as well. High capital and operating 
costs often make ship owners indecisive. The added volume and weight attributed to re-liquefaction plants may lead to a drop in cargo capacity or a losing chance for optimal placement of other onboard equipment to some extent.

Daewoo Shipbuilding \& Marine Engineering Co., Ltd., one of the world's largest shipyards based in South Korea, has developed a novel re-liquefaction system known as PRS (Partial Re-liquefaction System) to resolve these issues. A distinct advantage of this system is that it liquefies a sound proportion of BOG evaporated from LNG tanks although it is much smaller in size in comparison with conventional types of re-liquefaction systems (Lee, 2015).

Meanwhile, the growing concerns on the marine pollution have urged IMO (International Maritime Organization) and local authorities to grapple with finding ways to reduce emissions from ship activities. In the case of large LNG trading tankers ranging from 200,000 to $260,000 \mathrm{~m}^{3}$, about $15 \mathrm{MW}$ of electric load is required for use; the electricity is produced from onboard generators running on either diesel or gas which significantly contribute to marine air pollution. Of this amount, 5-7 MW is consumed only for LNG re-liquefaction, thereby it can be confirmed that the environmental impact associated with operating LNG re-liquefaction systems may be far higher than a negligible level (Sinha and Nik, 2012). This issue is projected to become considerably serious with the rising popularity of LNG and carriers.

Although the marine industry has been flooded with new systems, which are introduced more and more and faster and faster, the brevity of current maritime regulations often overlooks their environmental impacts. In response, it may be vital to evaluate the adverse effects of LNG re-liquefaction systems on the environment. To answer the fundamental question, posed in this research, on whether the proposed system can be an effective solution to cleaner shipping in comparison to other existing systems, this paper was motivated to adopt the theory of life cycle assessment (LCA) as an effective method to investigate the cradle-to-grave environmental impact of certain systems engaged in areas where regulations are premature. 


\subsection{Past research}

A variety of LCA studies in the marine sector has been identified as listed in Table 1, which can be divided into four major categories: LNG, marine fuels, marine systems and ships. Notable points from them are described briefly as follows:

For the LNG including LNG fueled vehicles, not necessarily limited to waterborne transportation, Venkatesh et al. (2011) conducted LCA of LNG uses in a nation with adopting probabilistic models considering uncertain factors. Shi et al. (2015) discovered that LNG remanufactured engines were eco-friendlier than diesel ones as producing less emissions during their operation although more energy and materials were required for their LNG components. By contrast, Sen et al. (2017) argued that trucks running on $\mathrm{CNG}$ (Compressed Natural Gas) could be more environmentally detrimental than their diesel counterparts especially in terms of GWP (Global Warming Potential). Mallapragada et al. (2018) estimated GWP and water consumption ascribed to Marcellus shale gas for an electricity generation purpose in various importers with employing the up-to-date field data and methane emissions rates obtained by a series of experiment. Zhang et al. (2018) investigated various emission levels under different LNG usage scenarios and suggested case-by-case approaches as each case encountered unique problems during their lifecycles. Speirs et al. (2019) conducted extensive research on determining the environmental benefits of using LNG as transportation fuels; the research findings highlighted that the use of NG as fuel of trucks and ships would reduce GHG by up to $16 \%$ and $10 \%$ respectively. Pizzol (2019) compared two ways of freight transport and concluded that integrated logistics using both trucks and ships together would be a better option than only using trucks for given supply chain scenarios. A specific LNG supply case was dealt with by three independent research groups from environmental perspectives and one of their conclusions implied that data depending on the region and operational profile would be more influential on the results than establishing sound methodologies and reasonable assumptions applied to the analysis (Nie et al., 2020). Yuan et al. (2020) pointed out the necessity of system optimization in accordance with regional gas composition by focusing on the emissions 
produced during NG re-liquefication process in various cases.

As for the marine fuels, Ma et al. (2012) presented that ships which adopted $\mathrm{SO}_{\mathrm{x}}$ (Sulphur Oxides) abatement systems to comply with $\mathrm{SO}_{\mathrm{x}}$ regulations would be better from a holistic environmental standpoint than using LSFO (Low Sulphur Fuel Oil). Bengtsson et al. (2011) showed the need for alternatives to traditional marine fuels to attain a considerable decline in pollutants. Brynolf et al. (2014) emphasized that renewable sources such as biomass should be used to curtail GWP holistically. Gilbert et al. (2018) claimed that the use of energy and environmentally harmful materials should be reduced at fuel production stage. The significance of optimal fuel supply routes in reducing emissions was highlighted by Hwang et al. (2019).

In terms of the marine systems, Alkaner and Zhou (2006) suggested focal points to lower burdens to nature in applying MCFCs (Molten Carbonate Fuel Cell) to commercial ships. Strazza et al. (2010) revealed that the use of biofuels at fuel production stages could lead to a considerable reduction in the total emissions produced from SOFCs (Solid Oxide Fuel Cell) as a power generation option onboard. Basurko and Mesbahi (2014) argued that electro-chemical oxidation types would be suitable for secondary ballast water treatment units than ultraviolet options because the latter ones needed toxic substances for their parts. Ling-Chin and Roskilly (2016)indicated that a marine system could outperform others with the same function from environmental perspectives; however, it might not necessarily mean that the system could be better throughout all kinds of emission. LCA was integrated with economic assessment for marine systems by Jeong et al. (2018), which was further strengthened for more appropriate decision-making with technical considerations added (Jeong et al., 2019). (Wang et al., 2019)) stressed that the improvement of power conversion efficiency should be critical in implementing solar panels on ships to reduce pollutants attributable to auxiliary diesel engines. (Wang et al., 2020)) also demonstrated that the change in engine configurations could contribute to lowering emission levels by operating engines within their efficient ranges. (Iannaccone et al., 2020) found that high pressure dual fuel engines had the least GWP potentials but considered them less sustainable given their potential safety issues. 
Regarding the ships, Cucinotta et al. (2017)conducted towing tank tests to estimate the fuel consumption of yachts made by different methods and the test results were employed in measuring emissions on the operational phase of the yachts. Effects on human health were highlighted across the whole ship recycling processes, which proved that LCA could enable extensive environmental evaluation (Rahman et al., 2016). Nian and Yuan (2017) proposed a navigation speed of tankers which might be most environmentally favorable by considering various ships and possible routes. Favi et al. (2018) established a user-friendly framework where essential data and models related to the marine context were available, thereby helping designers carry out LCA at an early design stage. Hua et al. (2019) revealed that varied operation conditions of engines played an important role in quantifying pollutants. Tuan and Wei (2019) examined emissions from detailed shipbuilding processes upon which similar studies had not touched.

What was agreed from the past research were that LCA would be an effective tool that could help us to estimate not only holistic environmental impacts of subjects but also discretize those impacts into the smallest levels of activities from the birth to the end-of-life. As a result, the full description of the environmental benefits or harms relative to subject items can be obtained in the process of LCA so that areas that need to be improved to reduce emissions could be identified at hand.

The LCA publications in Table 1 are highly focused on comparing various energy sources (referring to the research in the categories of LNG vehicles, marine fuels, marine systems), shipbuilding and navigation (referring to the research in the category of ships). The following past research related to LNG re-liquefaction systems applicable to LNG carriers are highly laden with their technical challenges and novelties: designing LNG re-liquefaction systems for small scale LNG carriers Nekså et al. (2010); development of a more energy-efficient PRS system by exergy analyses Choi et al. (2018); economic assessment Kim et al. (2019). Overall, those research processes and results hardly offer an insight into the influence of LNG re-liquefaction systems on the environment.

\subsection{Aim and novelty}


While a growing number of LNG carriers adopt LNG re-liquefaction systems, the scarcity of the relevant studies often mis-guides us on overlooking or underestimating their holistic impacts on air pollution. It motivated this research to have been born by aiming at evaluating the holistic environmental impact of LNG re-liquefaction systems, while seeking for a better way to reduce assorted harmfulness.

To conceptualize the full BOG reliquefication, this paper introduces the PRS and proposes two credible combinations of this system with existing re-liquefaction plants, namely PRS + SMR (Single Mixed Refrigerant) and PRS + MRS (Methane Refrigerant System), which were, then, compared to the conventional system types: the SMR, the MRS and the Enhanced SMR.

The novelty of this paper can be placed on the fact that it is a proactive response to the industrial demands as the first attempt to investigate the holistic environmental impacts relative to the proposed five re-liquefaction systems. Therefore, it is believed to offer a pragmatic intuition about quantitative environmental benefits of using proper systems for the future LNG vessels and even for LNG offshore units. 
Table 1. List of LCA studies in the marine sector

\begin{tabular}{|c|c|c|}
\hline LCA categories & Subjects & Authors and dates \\
\hline \multirow{9}{*}{$\begin{array}{c}\text { LNG } \\
\text { (including LNG }\end{array}$} & Domestic usage of LNG in a country which was produced in the country or imported from other nations & Venkatesh et al. (2011) \\
\hline & Remanufactured LNG and diesel engines & Shi et al. (2015) \\
\hline & Class 8 high duty trucks powered by various alternative fuels including $\mathrm{CNG}$ & Sen et al. (2017) \\
\hline & Marcellus shale gas extracted in the USA for power generation in importing countries & Mallapragada et al. (2018) \\
\hline & Three LNG uses scenarios (hydrogen generation, power production and transport) & Zhang et al. (2018) \\
\hline & NG as fuel for trucks and ships (four existing LNG dual fuel marine engines) & Speirs et al. (2019) \\
\hline & Two cargo transport cases: trucks only and trucks with the help of ships including LNG fueled ferries & Pizzol (2019) \\
\hline & A particular LNG chain from Canada to China for generation of electricity by three different research teams & Nie et al. (2020) \\
\hline & Liquefaction process of NG in diverse regions of China & Yuan et al. (2020) \\
\hline \multirow{5}{*}{ Marine fuels } & HFO with several $\mathrm{SO}_{x}$ (Sulphur Oxides) scrubber systems and LSFO (Low Sulphur Fuel Oil) & Ma et al. (2012) \\
\hline & HFO (Heavy Fuel Oil), MGO (Marine Gas Oil), LNG and the liquid fuel by means of GTL (Gas to Liquid) technology & Bengtsson et al. (2011) \\
\hline & LNG, LBG (Liquified Biogas), methanol and bio-methanol as marine fuel & Brynolf et al. (2014) \\
\hline & LNG, methanol, $\mathrm{LH}_{2}$ (Liquid Hydrogen), biodiesel, SVO (Straight Vegetable Oil), bio-LNG and traditional fuels & Gilbert et al. (2018) \\
\hline & A bulk carrier which runs on $\mathrm{LNG}$ and $\mathrm{MGO}$ & Hwang et al. (2019) \\
\hline \multirow{9}{*}{ Marine systems } & MCFCs and diesel engines & Alkaner and Zhou (2006) \\
\hline & Methanol fueled SOFCs as an auxiliary power system & Strazza et al. (2010) \\
\hline & Three ballast water treatment systems & Basurko and Mesbahi (2014) \\
\hline & Retrofitted and new-built power systems which introduce noble technologies & Ling-Chin and Roskilly (2016) \\
\hline & A hybrid engine in comparison with diesel-mechanical and diesel-electric engines & Jeong et al. (2018) \\
\hline & Three marine LNG fueled propulsion systems for LNG carriers & (Jeong et al., 2019) \\
\hline & Solar panel systems for propulsion applicable to a short trip ferry & (Wang et al., 2019) \\
\hline & Five different engine configurations of a tugboat & (Wang et al., 2020) \\
\hline & Three sorts of LNG fuel systems compared to a traditional engine which uses MGO on a cruise ship & (Iannaccone et al., 2020) \\
\hline
\end{tabular}




\begin{tabular}{|l|l|l|}
\hline \multirow{4}{*}{ Ships } & A glass-reinforced plastic yacht by means of two different building methods & Cucinotta et al. (2017) \\
\cline { 2 - 3 } & Steel gained from ship recycling and newly produced steel from iron ore & Rahman et al. (2016) \\
\cline { 2 - 3 } & A wide range of oil tanker cases & Nian and Yuan (2017) \\
\cline { 2 - 3 } & Three kinds of yachts whose hulls and superstructures are made of different materials & Favi et al. (2018) \\
\cline { 2 - 3 } & Container vessels which run on HFO or LNG from steel production to ship's operation & Hua et al. (2019) \\
\cline { 2 - 3 } & A Panamax bulk carrier from raw material collection to ship construction & Tuan and Wei (2019) \\
\hline
\end{tabular}




\section{Approach}

LCA is an approach to holistically assess potential environmental effects of various elements, products and systems from cradle to grave (ISO, 2006). By adopting the basic concept of generic LCA, this paper was organized to evaluate the performance of the proposed systems. The proposed framework is shown in Fig. 1.

\section{LCA stage 1: Goal and Scope Definition}

Five re-liquefaction systems:

- SMR, PRS + SMR, Enhanced SMR, MRS and PRS + MRS

\section{LCA boundary:}

- Cradle to grave

( Manufacture - Installation - Use - Recycle including fuel production phase )

\section{LCA stage 2: Inventory Analysis (LCl)}

Data collection:

Power Consumption Analysis

- Specifications of each system

- Case LNG carrier $\left(174,200 \mathrm{~m}^{3}\right)$

\section{LCA modelling and $\mathrm{LCI}$ results}

\section{LCA stage 3: Impact Assessment (LCIA)}

\section{LCIA results:}

- Classification of LCA results

- Appliance of characterisation factors

- Five impact categories : GWP, PM, POCP, EP and AP

LCA stage 4: Interpretation

Fig. 1. LCA framework for LNG re-liquefaction systems

\subsection{Stage 1: Goal and scope definition}


The goal of this LCA was to demonstrate environmental benefits of the PRS by comparing five probable re-liquefaction systems: the SMR; the PRS + SMR; the Enhanced SMR; the MRS; and the PRS + MRS. Those systems were designed and modelled in consideration of available options for LNG carriers and their capacity demand. Afterwards, relevant data for the analysis such as specifications of the systems and embodied energy for certain work was collected within the LCA boundary established in the first stage of LCA.

\subsubsection{Introduction to PRS and five re-liquefaction systems}

The proposed five re-liquefaction systems are modelled based on the actual designs adopted in Daewoo Shipbuilding and Marine Engineering Ltd (DSME).

The key principle of the PRS is to utilize the cryogenic temperature (approximately $-100^{\circ} \mathrm{C}$ to $-130^{\circ} \mathrm{C}$ ) of the BOG coming directly from LNG storage tanks to liquefy BOG by pressurizing it up to around 300 bar (Yun, 2016). The cooled BOG from a heat exchanger is throttled by a J-T valve (Joule-Thomson valve). In the process, the pressure of BOG plunges leading to a drastic decline in the temperature and the extremely cooled mixture of BOG and LNG are then separated by a separator.

The BOG is pressurized up to 300 bar by a series of LNG compressors (BOG and Booster comps in Fig. 2) for LNG fuel injection into dual fuel engines of MAN B\&W, which is one of the popular marine engine systems for new-built LNG carriers (Kjeld and Rene, 2009). This implies that no extra compressor is needed if the presented engine is adopted as a propulsion option.

In contrast to other LNG re-liquefaction systems, the PRS does not require an additional refrigerant cycle. Instead, the BOG generated from LNG cargo tanks acts as a refrigerant in the system, making the system relatively simpler. However, the re-liquefaction capacity of the PRS is inherently less than those of other systems. This is due to the fact that although the BOG pressure rises to $300 \mathrm{bar}$, the temperature of the BOG coming from the tanks does not sufficiently low enough to liquefy all naturally 
evaporated gas. This system can be enhanced in terms of re-liquefaction capacity by arranging two PRS systems in series. A schematic diagram of Enhanced PRS is illustrated in Fig. 2. The PRS is often integrated with other types of re-liquefaction systems to increase re-liquefaction capacity. The PRS has proven to reduce the burden on ship's shoulders owing to its relatively low economic impact and compact size (Yun, 2016).

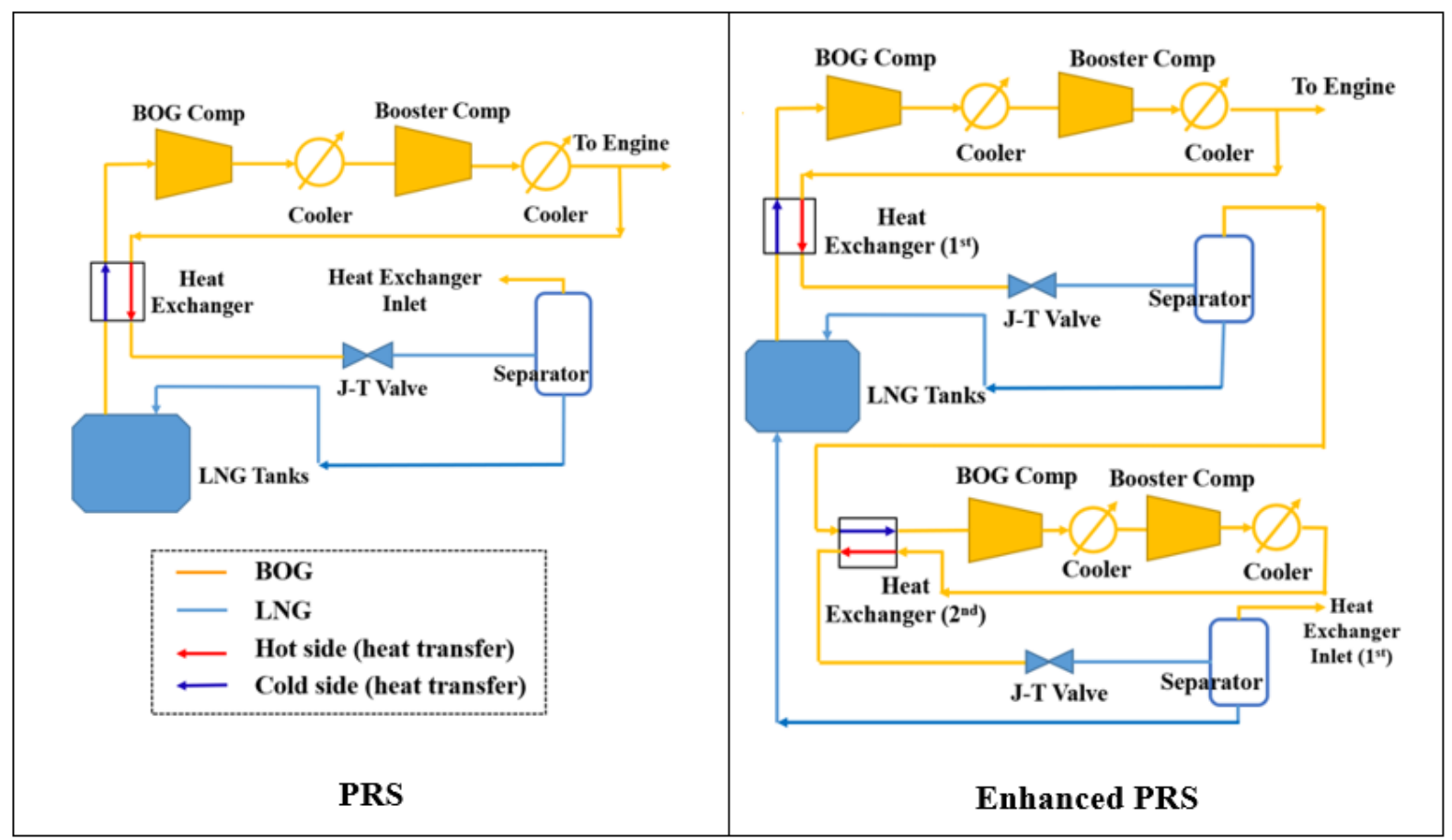

Fig. 2. Schematic diagrams of PRS and Enhanced PRS (Choi, 2018)

With the PRS concept as well as existing re-liquefaction systems, the following five credible options were modeled and each of them was briefly explained as below.

- SMR: the refrigerant of this system is largely composed of a mixture of hydrocarbon and nitrogen. It has an independent closed loop refrigeration cycle. The green loop in Fig. 3 (a) indicates the loop of the single-mixed refrigerant. The SMR is recognized for having high efficiency; however, maintaining a pre-set mixture ratio of the refrigerant causes a considerable amount of maintenance and operation expenditure.

- $M R S$ : it adopts the BOG as a refrigerant. Apart from this, its components and working principle 
are similar with those of the SMR. Since the BOG is directly employed as a cooling medium, a better operability is obtained compared to the SMR (see Fig. 3 (b)).

- $\quad P R S+S M R$ : the BOG is pre-liquefied at a PRS heat exchanger before flowing through a main heat exchanger of the SMR. Much less compressor work is required during the main refrigerant cycle since a handsome amount of BOG is turned into LNG via the PRS system in advance (see Fig. $3(\mathrm{c}))$.

- Enhanced SMR: it also employs the cryogenic temperature of the BOG originated from the LNG storage tanks by an additional loop as depicted in Fig. 3 (d). Unlike the PRS + SMR, an extra boosting compressor, a heat exchanger and a cooler are not required.

- $P R S+M R S:$ the MRS is combined with the PRS to raise its re-liquefaction capacity. While the mechanism is almost identical to the PRS + SMR, the only difference is that the BOG itself serves as its refrigerant (see Fig. 3 (e)). 


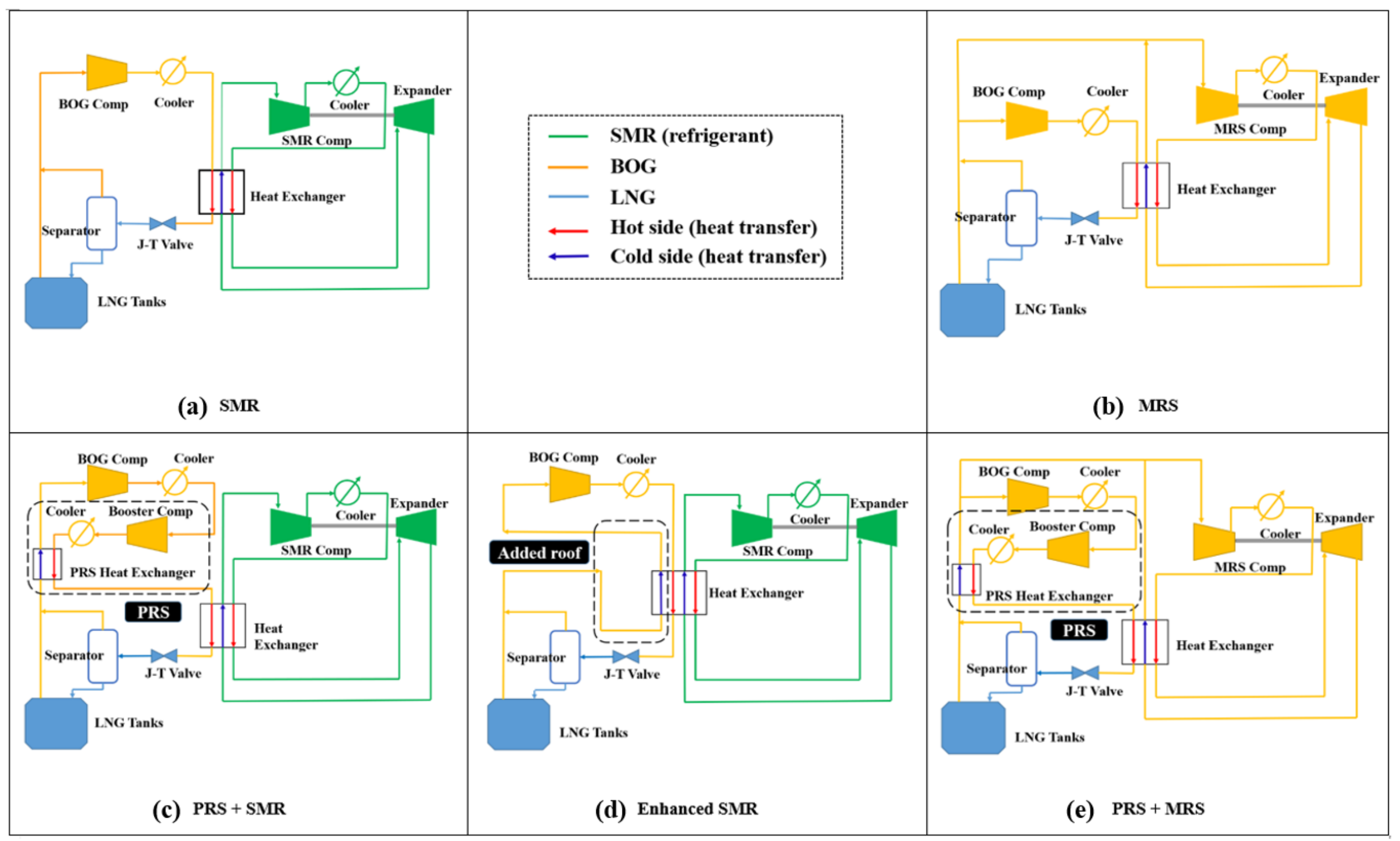

Fig. 3. Schematic diagrams of five re-liquefaction systems ((Choi, 2018; Gómez et al., 2013)) 


\subsubsection{Boundaries}

Each case system was designed to have a capacity of $4,000 \mathrm{~kg} / \mathrm{h}$ in consideration of their system specifications. In other words, the functional unit of the five systems would be capable of re-liquefying $4,000 \mathrm{~kg}$ of the BOG in an hour for 25 years for a comparison purpose.

The scope and the LCA boundary for the five re-liquefaction systems are specified in Eq. (1). Their life cycles have been split into five phases: manufacturing, installation, fuel production, use and recycling (cradle to grave). The $\mathrm{P}$ in the equation represents pollutants and the fuel production phase is denoted as fuel for simplicity.

$$
\mathrm{P}_{\text {total }}=\mathrm{P}_{\text {manufacturing }}+\mathrm{P}_{\text {Installation }}+\mathrm{P}_{\text {fuel }}+\mathrm{P}_{\text {use }}+\mathrm{P}_{\text {recycling }}
$$

The boundary and assumptions of this LCA are summarized as below:

- Life stages and assorted activities were selected based on the LCA findings from past research in which specified dominant activities contribute to the environmental contamination,

- The manufacturing phase ranges from raw material production to product assembly in the factory,

- Regarding the manufacturing phase, the embodied energy for part deformation was not able to be added owing to lack of consistent data. According to the LCA reference book (Ashby, 2012) employed for this assessment, a similar or lower level of energy tends to be consumed in comparison with material casting,

- In terms of the energy embodied in the installation phase, welding was considered a core energy consuming activity since module-based equipment would be shipped from manufacturers and assembled on ships,

- The life of a case vessel was thought to be 25 years, a typical lifetime of LNG carriers,

- Re-liquefaction modules were assumed to be fully recycled, but a pugging process is not considered as the BOG was assumed to be $100 \%$ consumed, 
- The maintenance phase was not included in the study scope because its contribution was expected to be not significant to the total emissions. This is due to the fact that harmful environmental potentials on this stage are related to spare parts and a few major overhauls unlike the maintenance of the entire ship (Jeong et al., 2018),

- The adverse impact of transportation activity was neglected as manufacturing to onboard logistics depends on how the scenario was designed. If the same logistics applies to each system, the transportation effect is very identical in all cases,

- All energy input was made in the form of electricity,

- In the LCA models, all manufacturers were assumed to be in China and electricity was to be produced by Chinese power plants for consistency; based on the fact that China is acknowledged as a top shipbuilding country where LNG carriers are currently built (Gourdon and Steidl, 2019),

- The emissions involved in generating electricity which was used as the key energy source for manufacturing, installation and recycling were calculated according to the information in the GaBi database,

- The consumed electricity onboard has been regarded to be generated from HFO, which is the most typical type of marine fuel,

- Based on the GaBi database, environmentally detrimental potentials associated with HFO production were measured,

- The life stage of the fuel production encompasses fuel extraction, transportation, refinery and supply to onboard. 


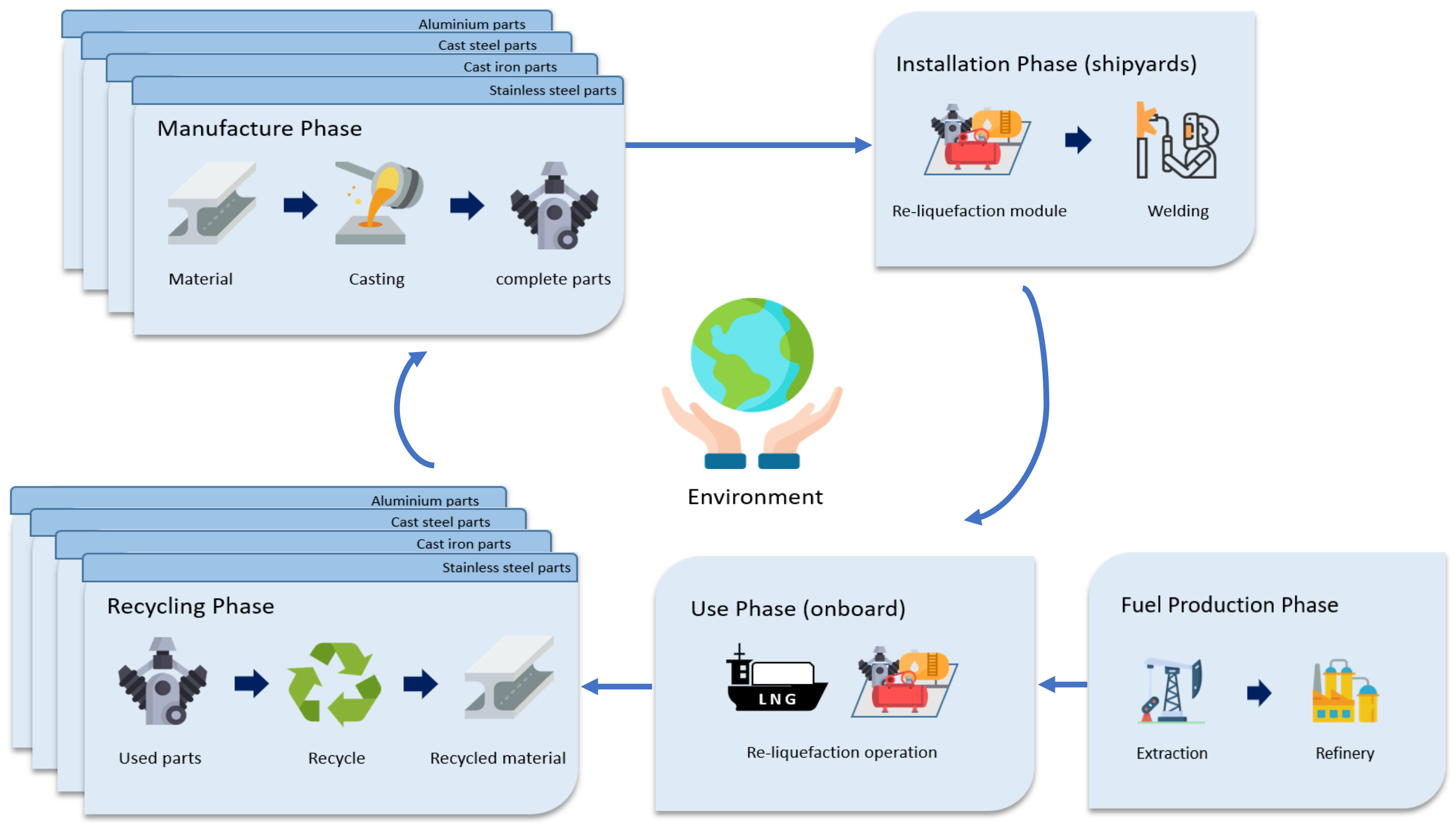

Fig. 4. LCA scope and boundary for LNG re-liquefaction systems 


\subsubsection{Calculation of power consumption}

To calculate the electricity consumption for each re-liquefaction system, an iterative process was engaged in this framework. A commercial process simulation software, called Aspen HYSYS, was utilized.

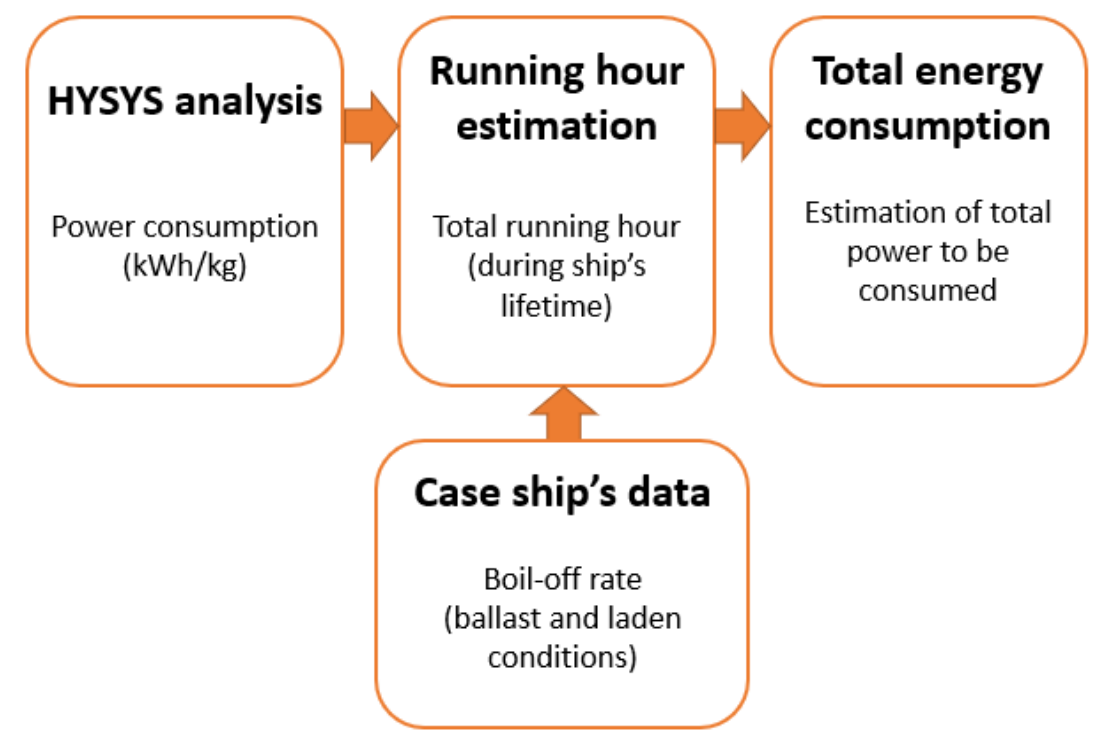

Fig. 5. Calculation of energy consumption on the use phase

The employed models are presented in Fig. 6. The refrigerant for SMR generally adopts C1 (methane), C2 (ethane), C3 (propane) and N2 (nitrogen). Since C2 and C3 are mostly used as refrigerants for onshore LNG plants rather than LNG carriers, their usage was not considered in the analysis. In contrast, the cooling medium for MR is only composed of $\mathrm{C} 1$. Concerning property packages, the analysis was conducted based on Peng-Robinson, which is a widely used model for simulating gaseous media such as the BOG and the other refrigerants at ambient temperature (Hamid, 2007). In the models, the refrigerant compressor and the expander were linked by a common gearbox, called compander through which the rotational force produced from the expander was applied for operating the compressor. 


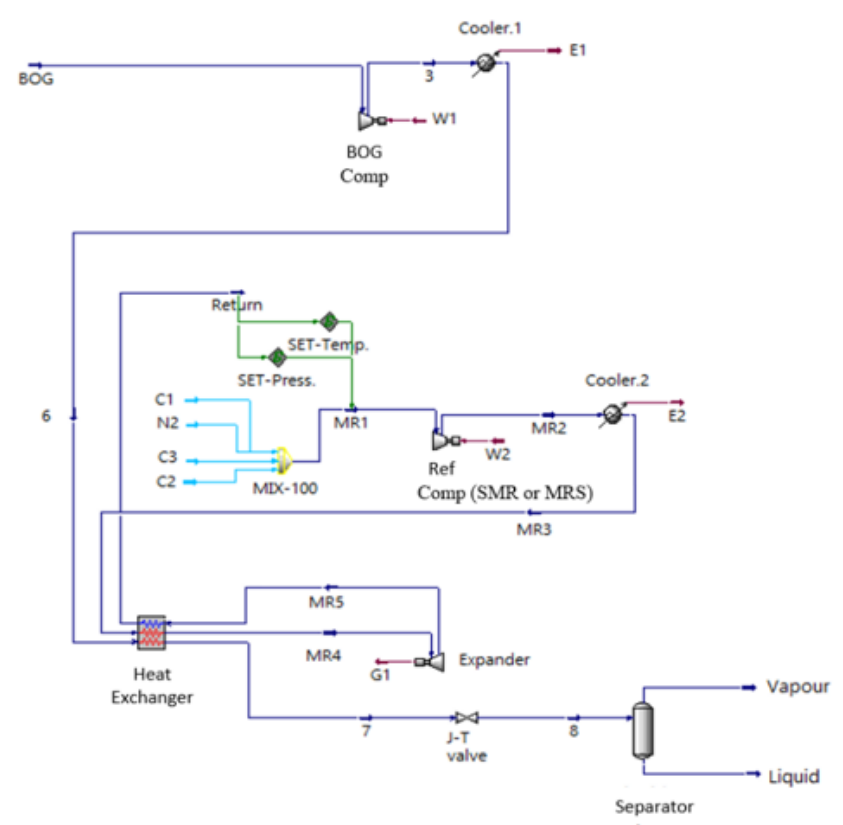

SMR and MRS

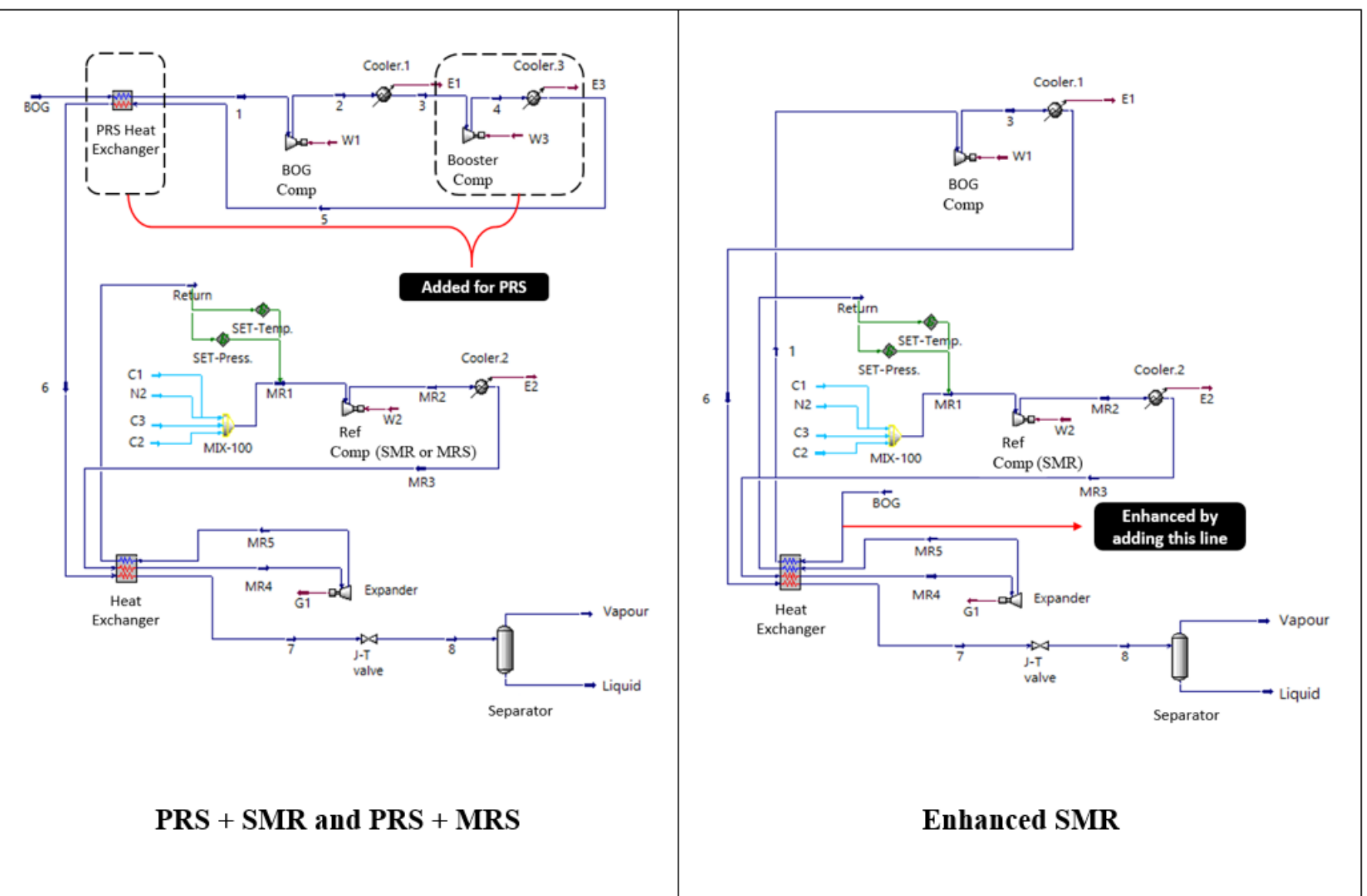

Fig. 6. Aspen HYSYS models 
General input parameters applied for HYSYS analysis was summarized in Table 2. This paper had to inevitably make some assumptions regarding the system efficiency, which is highly dependent on types, manufacturers and working conditions and so on, thereby it was not proper to define the system efficiency as a single number in reality. Given that the efficiency of compressors is generally ranged between $50 \%$ and $90 \%$, the adiabatic efficiency of compressors was assumed to be $75 \%$. On the other hand, the efficiency of heat exchangers is highly relied on operating times, flow conditions, etc. so that it was assumed to be operated in the perfect conditions (100\% efficiency). It may be true that those assumptions may cause deviations in analysis results when compared to actual system operations to some extent. Nevertheless, those assumptions will never misguide us into wrong conclusions or any dangerous misunderstanding in research findings; as long as all systems are compared in the same condition, the general trends of results will surely not be changed.

Table 2. Input parameters of HYSYS analyses (By curtesy of Daewoo Shipbuilding and Marine Engineering Ltd.)

\begin{tabular}{|c|c|}
\hline Input flow & $4,000 \mathrm{~kg} / \mathrm{h}$ at $-120^{\circ} \mathrm{C}$ \\
\hline Temperature of cooling media (coolers) & $40^{\circ} \mathrm{C}($ seawater or ambient temperature) \\
\hline Pressure drop via a cooler & $50 \mathrm{kPa}$ \\
\hline Adiabatic efficiency of compressors & $75 \%$ \\
/ heat exchangers & $1100 \%$ \\
\hline Pressure decline (hot side of heat exchangers) & $100 \mathrm{kPa}$ \\
\hline Pressure decline (cold side of heat exchangers) & $20 \mathrm{kPa}$ \\
\hline Pressure (J-T valve downstream) & 1 atm (equal to those of cargo tanks) \\
\hline SMR composition & $\mathrm{C} 1(0.486), \mathrm{C} 2(0.0), \mathrm{C} 3(0.0)$ and $\mathrm{N} 2(0.514)$ \\
\hline MR composition & $\mathrm{C} 1(1.0), \mathrm{C} 2(0.0), \mathrm{C} 3(0.0)$ and $\mathrm{N} 2(0.0)$ \\
\hline
\end{tabular}

The results obtained from these simulations are shown in Table 3. It is clearly revealed that the PRS 
combined systems - the PRS+SMR and the PRS+MRS - could improve the system performance, thereby lowering the power consumption. For instance, the PRS + SMR required least energy with consuming $1.23 \mathrm{kWh}$ for treating $1 \mathrm{~kg}$ of BOG. By contrast, the MRS consumed $1.64 \mathrm{kWh}$ for reliquefying the same amount of BOG, meaning that the PRS + SMR would be $33 \%$ more efficient than the MRS. The estimated electricity load, as a simulation result, was input for estimating total energy consumption on the operation stage of the re-liquefaction systems, taking into account the actual data navigation and BOR (Boil-Off Rate) - of the case ship. 
Table 3. The results of HYSYS analyses

\begin{tabular}{|c|c|c|c|c|c|c|}
\hline Description & Unit & SMR & PRS + SMR & Enhanced SMR & MRS & PRS + MRS \\
\hline Methane (C1) & $\mathrm{kg} / \mathrm{h}$ & 15,700 & 12,500 & 14,000 & 24,800 & 18,200 \\
\hline Nitrogen (N2) & $\mathrm{kg} / \mathrm{h}$ & 29,000 & 16,700 & 21,500 & - & - \\
\hline BOG comp duty & $\mathrm{kW}$ & 457.6 & 899.2 & 762.9 & 457.6 & 897.1 \\
\hline Ref comp duty & $\mathrm{kW}$ & 6,685 & 4,530 & 5,417 & 7,106 & 4,755 \\
\hline Booster comp duty & $\mathrm{kW}$ & - & 148.0 & - & - & 138.3 \\
\hline Cooler 1 and 2 & $\mathrm{~kW}$ & $6,861.1$ & $5,583.3$ & $6,083.3$ & 7,250 & $5,777.8$ \\
\hline Expander & $\mathrm{kW}$ & 949.4 & 656.2 & 778.8 & 982.8 & 681.6 \\
\hline Point 6 & ${ }^{\circ} \mathrm{C} @$ bar & $40 @ 15.5$ & $-70 @ 26.5$ & $40 @ 15.5$ & $40 @ 15.5$ & $-70 @ 25.5$ \\
\hline Point 7 & ${ }^{\circ} \mathrm{C} @$ bar & -162.5@14.5 & $-162.5 @ 25.5$ & -162.5@14.5 & $-162.5 @ 14.5$ & $-163 @ 24.5$ \\
\hline Power required & $\mathrm{kW}$ & 6,193 & 4,921 & 5,401 & 6,581 & 5,108 \\
\hline Energy / BOG in kg & $\mathrm{kWh} / \mathrm{kg}$ & 1.55 & 1.23 & 1.35 & 1.64 & 1.28 \\
\hline
\end{tabular}

* 'point 6' and 'point 7' indicate the points marked in the HYSYS models shown in Fig. 6. 


\subsection{Stage 2: Life cycle inventory analysis (LCI)}

The LCI of the five systems were modelled under the platform of a LCA software, GaBi (PE, 2018). The estimated power consumptions from HYSYS analysis were input into the LCI.

Other relevant data were collected and input to the analysis according to the goal and scope established in the previous section 2.1. The configuration of each re-liquefaction system was simplified into major components. The weight and composition of materials used for those systems were estimated on the basis of data from manufacturers: Tractebel (Gerdsmeyer and Isalski, 2005) and Wärtsilä (Melaaen, 2013). Those were largely classified into four metal components: stainless steel, cast iron, cast steel and aluminum. Table 4 lists the estimated specifications of the five options. The compander represents a combination of compressors and expanders.

Table 4. Collected data regarding specifications

\begin{tabular}{|c|c|c|c|c|c|}
\hline & SMR & PRS + SMR & Enhanced SMR & MRS & PRS + MRS \\
\hline Sort of component & \multicolumn{5}{|c|}{ Number of components (Unit: no. of items) } \\
\hline Compressor & 1 & 2 & 1 & 1 & 2 \\
\hline Compander & 1 & 1 & 1 & 1 & 1 \\
\hline Cooler & 2 & 3 & 2 & 2 & 3 \\
\hline Heat exchanger & 1 & 2 & 1 & 1 & 2 \\
\hline Refrigerant tank & 1 & 1 & 1 & - & - \\
\hline Sort of material & \multicolumn{2}{|c|}{ Estimation of weight and material composition (Unit: ton) } \\
\hline Stainless steel & 62.3 & 66.0 & 64.9 & 66.6 & 67.3 \\
\hline Cast iron & 24.9 & 24.0 & 23.6 & 21.1 & 22.4 \\
\hline Cast steel & 20.4 & 21.6 & 21.2 & 17.8 & 20.1 \\
\hline Aluminium & 5.7 & 8.4 & 8.3 & 5.6 & 8.3 \\
\hline Total weight & 113.3 & 120.0 & 118.0 & 111.0 & 118.0 \\
\hline
\end{tabular}


Dixit et al. (2012) divided the total energy use of a building for its lifetime into two categories: the operational energy and the embodied energy. The former represents the energy consumed while the building was operated. The latter describes a sum of all the other energy spent on its part production, construction, transportation and the end of the life phase. If the concept is applied to this LCA study, the two energy categories can be expressed as Eq. (2) and Eq. (3). The E in the formulas denotes energy and the fuel stands for fuel production.

$\mathrm{E}_{\text {embodied }}=\mathrm{E}_{\text {manufacturing }}+\mathrm{E}_{\text {installation }}+\mathrm{E}_{\text {recycling }}$

$\mathrm{E}_{\text {operational }}=\mathrm{E}_{\text {use }}+\mathrm{E}_{\text {fuel }}$

$\mathrm{E}_{\text {total }}=\mathrm{E}_{\text {embodied }}+\mathrm{E}_{\text {operational }}$

The embodied energy on the manufacturing and recycling phases was quantified based on the data shown in Table 5.

Table 5. Embodied energy consumption for four main materials (Ashby, 2012)

\begin{tabular}{|c|c|c|c|c|}
\hline Unit: $\mathbf{M J} / \mathbf{k g}$ & Stainless steel & Cast iron & Cast steel & Aluminum \\
\hline Material production & $81.0-88.0$ & $16.0-20.0$ & $31.0-34.0$ & $200.0-220.0$ \\
\hline Casting & $10.0-12.0$ & $10.0-11.0$ & $10.9-12.0$ & $11.0-12.2$ \\
\hline Recycling & $11.0-13.0$ & $10.0-11.0$ & $7.7-9.5$ & $22.0-33.0$ \\
\hline Total & $113.0^{*}$ & $42.0^{*}$ & $55.5^{*}$ & $265.2^{*}$ \\
\hline
\end{tabular}

* highest values were taken for more conservative calculations

Concerning the installation stage, the electricity used for welding process was estimated as $1,361.32$ $\mathrm{MJ} /$ ton according to a research paper. The study presented that a 1,700 gross tonnage ship would need $117.2 \mathrm{~km}$ of welding and $15 \mathrm{MJ}$ of energy would be consumed for $1 \mathrm{~m}$ of welding line (Johnsen and Fet, 1999). 
An LNG carrier was selected as a case ship to investigate the environmental impacts of the proposed re-liquefaction systems on the use phase (operational energy). The cargo capacity of the case ship was $174,200 \mathrm{~m}^{3}$, representing a typical large LNG carrier. The ship's specification is described in Table 6 . It also shows the amount of the BOG naturally generated in both ballast and laden conditions. To calculate the amount of the BOG in $\mathrm{kg}$, the density of LNG was assumed to be $485 \mathrm{~kg} / \mathrm{m}^{3}$ (Dobrota et al., 2013).

Table 6. Case ship's specification, regular voyage and BOR (By curtesy of Hyundai LNG Co., Ltd.).

\begin{tabular}{|c|c|c|c|c|}
\hline \multicolumn{5}{|c|}{ LNG carrier (Membrane type tanks) } \\
\hline Length & $290.50 \mathrm{~m}$ & Gross tonnage & \multicolumn{2}{|c|}{115,541 tons } \\
\hline Breath & $47.61 \mathrm{~m}$ & Cargo capacity & \multicolumn{2}{|c|}{$174,200.73 \mathrm{~m}^{3}(100 \%)$} \\
\hline Depth & $26.50 \mathrm{~m}$ & Main engine & \multicolumn{2}{|c|}{$\begin{array}{c}\text { 5G70ME - C9.5 - GI } \times 2 \text { sets } \\
\text { (M-type Electronically controlled Gas } \\
\text { Injection) }\end{array}$} \\
\hline \multirow{2}{*}{1 Return voyage } & Ballast & Laden & In port & Total \\
\hline & 27 days & 30 days & 2 days & 59 days \\
\hline \multirow{2}{*}{ BOR } & \multicolumn{2}{|c|}{ Ballast voyage } & \multicolumn{2}{|c|}{ Laden voyage } \\
\hline & \multicolumn{2}{|c|}{$0.07 \% /$ day } & \multicolumn{2}{|c|}{$0.08 \% /$ day } \\
\hline
\end{tabular}

Table 7 shows the total BOG generated over the entire life stretch of the case ship and the corresponding running hours of the re-liquefaction plants. This case ship was assumed to be operated for 25 years with regular travels between the USA and South Korea; it is the actual voyage route. According to the ship operational profile, 155 voyages throughout the ship's lifetime were projected. The predicted running hour of re-liquefaction systems was drawn with a downtime of $5 \%$ considered given the regular maintenance of the ship and possible anchoring periods in off-peak seasons. 
Table 7. Running hour prediction in accordance with the case ship's BOR and usual voyage (By curtesy of Hyundai LNG Co., Ltd.).

\begin{tabular}{|c|c|c|}
\hline & Ballast voyage & Laden voyage \\
\hline BOG (kg / hour) & $2,464.17$ & $2,816.23$ \\
\hline Daily BOG (kg / day) & $5.91 \times 10^{4}$ & $3.76 \times 10^{4}$ \\
\hline BOG (for 25 years) & $2.48 \times 10^{8} \mathrm{~kg} \times 10^{8} \mathrm{~kg}$ \\
\hline Total BOG (for 25 years) & \multicolumn{2}{|c|}{$5.62 \times 10^{8} \mathrm{~kg}$} \\
\hline Maximum run hours & $1.40 \times 10^{5}$ hours \\
\hline Estimated running hour & $1.33 \times 10^{5}$ hours (downtime $\left.5 \%\right)$ \\
\hline
\end{tabular}

The total fuel consumption of each system was calculated in the combination between the estimated running hour and the power consumption acquired by the HYSYS analyses. Since the electricity for reliquefaction is generated by onboard auxiliary generator engines, Eq. (5) was employed for calculating the amounts of required HFO. In the equation, an average of $190 \mathrm{~g} / \mathrm{kWh}$ was assumed as the SFOC (Specific Fuel Oil Consumption) in accordance with the engine maker's guidebook (MAN, 2020).

$$
\mathrm{F}=\mathrm{SFOC} \times \mathrm{P} \times \mathrm{H}
$$

Where,

$\mathrm{F}$ is the fuel consumption $(\mathrm{g})$;

SFOC represents the specific fuel oil consumption of the generator engine $(\mathrm{g} / \mathrm{kWh})$;

$\mathrm{P}$ denotes the required power of the considered re-liquefaction plants $(\mathrm{kW})$;

$\mathrm{H}$ is the running hour of the plants $(\mathrm{h})$.

The amounts of emissions on the use phase were calculated based on standardized emissions factors presented in Table 8 . 
Table 8. Emission factors (IMO, 2014)

\begin{tabular}{|c|c|c|c|c|c|c|c|}
\hline \multicolumn{7}{|c|}{ Emissions in kg per 1kg of HFO } \\
\hline $\mathrm{CO}_{2}$ & $\mathrm{NO}_{\mathrm{x}}$ & $\mathrm{SO}_{\mathrm{x}}$ & $\mathrm{PM}$ & $\mathrm{CO}$ & $\mathrm{CH}_{4}$ & $\mathrm{~N}_{2} \mathrm{O}$ & NMVOC \\
\hline 3.1 & $4.9 \times 10^{-2}$ & $5.3 \times 10^{-2}$ & $6.3 \times 10^{-3}$ & $2.4 \times 10^{-3}$ & $4.0 \times 10^{-5}$ & $1.6 \times 10^{-4}$ & $1.8 \times 10^{-3}$ \\
\hline
\end{tabular}

\subsection{Stage 3: Life cycle impact assessment (LCIA)}

Under the same GaBi platform, Stage 3 began to classify numerous types of emissions and combine them into representative units by applying characterization factors. LCIA results were presented with a variety of impact categories. Of these, this paper was focused on estimating the five impact categories for a simple reason that they have been mainly concerned in the marine sector:

- GWP(Global Warming Potential): global warming is most well-known phenomenon which the earth is facing. IMO has driven decarbonization in the shipping industry with a goal of halving the $\mathrm{CO}_{2}$ (carbon dioxide) emission level of 2008 by 2050 ,

- $\quad P M_{2.5}$ (Particulate Matter): it refers to fine particles and droplets, which causes not only poor visibility but also respiratory problems. This pollutant is limited by IMO MARPOL Annex VI Regulation 14,

- POCP (Photochemical Ozone Creation Potential): a high concentration of ozone near the ground has detrimental effects on human health and plants. NMVOC (Non-Methane Volatile Organic Compound) is a culprit of POCP so that the release of NMVOC is restricted by IMO MARPOL Annex VI Regulation 15,

- EP (Eutrophication Potential): excessive nutrients can be added to soils or waters. IMO MARPOL Annex VI Regulation 13 controls nitrogen oxides (a great contributor for EP) released from the combustion of marine engines,

- AP (Acidification Potential): air pollutants are transformed into acids, which can acidify soils and waters. The sulphur content (AP contributor) of marine fuel oils are regulated by IMO 
MARPOL Annex VI Regulation 14.

The results of the impact categories were driven through two LCIA methods: CML2001 presented by the institute of Leiden University and ILCD (International reference Life Cycle Data system) developed by European Commission. ILCD was chosen to measure eutrophication effects particularly on the marine environment. CML2001 showed AP values in $\mathrm{kg}$, which was consistent with the other four categories from ILCD.

The CML2001 is the most common method across the industries. In particular, the vast majority of LCA research in the marine industry has adopted CML2001 as the standard method (it can be easily confirmed once having a quick look at past maritime research referenced in this paper). To keep the consistency with the current practice, the CML2001 would be helpful for understanding and comparison if any. For a cross-check purpose, this paper adopted a second method of ILCD; since the current research was based in the UK, a view of European standards was thought of as necessary.

\subsection{Stage 4: Interpretation}

Considering data quality, assumptions and methods according to the goal and scope declared in Stage 1 , several variables would need to be further investigated in order to confirm whether the results would be still consistent with the changes in those predefined parameters.

One variable is the change in the amount of electricity used by re-liquefaction systems. This factor could considerably affect the amount of air pollutants on the use phase of the considered systems, known as the most dominant stage of product's lifetime throughout the reviewed studies. Their operational profiles might vary chiefly owing to two reasons for their lifespan. There might be difference in the boil-off rate on account of sea conditions, ambient temperatures, the ageing of the systems, the use of BOG for onboard engines and more, which can bring about either an increase or decrease in electricity consumption. The other reason is the state of the re-liquefaction plants. Despite regular maintenance, a system is hardly kept in an optimal condition until the end of life. Four cases with a range from 80 to 
$120 \%$ of preset power consumption were simulated.

As the second variable, different fuels for onboard electricity generation were also examined to determine the impacts they would have on emissions levels as the electricity was supplied to the reliquefaction systems. The use of a different fuel could have a substantial influence on both emissions from its production and combustion. MGO and LNG scenarios were assumed instead of HFO. MGO has been used onboard ships to comply with stricter sulphur restrictions in certain sea areas called ECAs (Emission Control Areas). The BOG used to be burned almost solely by steam boilers in turbine-based ships; however, it started to be used by internal combustion engines with the development of dual fuel engines. Other types of ship as well as LNG carriers can be fitted with dual fuel propulsion engines along with dual fuel gensets as an option to satisfy the standards of the newly enforced sulphur cap in 2020.

The same SFOC as the HFO case was applied to the MGO one. As for the use of LNG, a SFGC (Specific Fuel Gas Consumption) of $150 \mathrm{~g} / \mathrm{kWh}$ was assumed and the pilot oil (HFO) consumption was set to 2.5 $\mathrm{g} / \mathrm{kWh}$ with model brochures from well-known engine manufacturers considered (MAN, 2020; WinGD, 2015). The emissions factors with regard to the two fuels taken from IMO's data are shown in Table 9.

Table 9. Emissions factors for MGO and LNG (IMO, 2014)

\begin{tabular}{|c|c|c|c|c|c|c|c|c|}
\hline \multicolumn{7}{|c|}{ Emissions in kg per 1kg of the specified fuels } \\
\hline & $\mathrm{CO}_{2}$ & $\mathrm{NO}_{\mathrm{x}}$ & $\mathrm{SO}_{\mathrm{x}}$ & $\mathrm{PM}$ & $\mathrm{CO}$ & $\mathrm{CH}_{4}$ & $\mathrm{~N}_{2} \mathrm{O}$ & $\mathrm{NMVOC}$ \\
\hline $\mathrm{MGO}$ & 3.2 & $4.6 \times 10^{-2}$ & $2.7 \times 10^{-3}$ & $8.9 \times 10^{-4}$ & $2.4 \times 10^{-3}$ & $4.0 \times 10^{-5}$ & $1.6 \times 10^{-4}$ & $1.8 \times 10^{-3}$ \\
\hline LNG & 2.8 & $7.8 \times 10^{-3}$ & $2.0 \times 10^{-5}$ & $1.8 \times 10^{-4}$ & $7.8 \times 10^{-3}$ & $5.1 \times 10^{-2}$ & $1.1 \times 10^{-4}$ & $3.0 \times 10^{-3}$ \\
\hline
\end{tabular}

Another factor to be considered is the BOR of the case LNG carrier. In this LCA study, the BORs were determined by the case ship's records. However, this parameter can be changed under various situations over life time, resulting in a significant effect on the LCA results. To demonstrate environmental benefits of the PRS, a sensitivity analysis for different BORs were conducted. Huan et al. (2019) 
presented that most newbuilt LNG carriers had a BOR of $0.1 \%$ /day. Based on this paper, $0.1 \%$ /day was chosen as a conservative case while $0.05 \%$ /day was opted for as an optimistic case with an improved cargo containment system. As for those two cases, the same declared BORs were applied to the calculations no matter whether the ship was loaded or not. To exemplify, the rate of $0.1 \%$ day was assumed for both its laden and ballast voyages in the case of the former case. Table 10 summarizes the predicted quantities of BOG and the estimation of lifetime running hours of re-liquefaction systems.

Table 10. Two scenarios with different BOGs

\begin{tabular}{|c|c|c|}
\hline BOR & $0.05 \% /$ day & $0.1 \% /$ day \\
\hline BOG (kg/hour) & $1,758.33$ & $3,520.83$ \\
\hline Daily BOG (kg/day) & $4.22 \times 10^{4}$ & $8.45 \times 10^{4}$ \\
\hline BOG (for 25 years) & $3.73 \times 10^{8} \mathrm{~kg}$ & $7.46 \times 10^{8} \mathrm{~kg}$ \\
\hline Maximum run hours & $9.33 \times 10^{4}$ hours & $1.87 \times 10^{5}$ hours \\
\hline Estimated running hour & $8.86 \times 10^{4}$ hours (downtime $5 \%$ ) & $1.77 \times 10^{5}$ hours (downtime $5 \%$ ) \\
\hline
\end{tabular}

The efficiency of heat exchangers has been selected as the last parameter to be verified. It can be defined as the actual transferred heat per the heat to be transferred in an ideal heat exchanger. The HYSYS analyses assumed the heat exchange efficiency to be equally ideal earlier. This variable can dictate how much electricity is consumed by the compressors of a re-liquefaction system; accordingly, it can be linked directly with the degrees of environmental impact caused by the use of onboard re-liquefaction systems. To confirm what extent the variable can alter the results of the assessment, three different heat exchange efficiencies have been taken into account, which were 70, 80 and $90 \%$.

After the consistency of the LCIA results were guaranteed through the described sensitivity analyses, conclusions were drawn with probable suggestions given the target audiences set in Stage 1 on the basis of the key findings of this assessment. 


\section{Results}

\subsection{Results of LCIA}

The five environmental potentials associated with the entire life stages are depicted in Fig. 7. Overall, it shows the PRS + SMR would be the most optimal option, whereas the MRS would be the worst from an environmental perspective. Regarding GWP, the MRS discharged $5.99 \times 10^{8} \mathrm{~kg} \mathrm{CO} 2$ eq., which was around $25 \%$ higher than the emission produced from the PRS + SMR. The PRS + MRS and the enhanced SMR came after the PRS + SMR with producing $4.66 \times 10^{8}$ and $4.93 \times 10^{8} \mathrm{~kg}$. The SMR released a comparable amount of emissions with the MRS, recording $5.64 \times 10^{8} \mathrm{~kg}$.

The very same trend was observed in regard to the other local pollutants. The MRS was the greatest producer in terms of all five categories. Again, the opposite was true with the PRS + SMR. It is noticed that the differences in results between the two options were analogous across all the impacts: GWP, PM, POCP, EP and AP. As for the other re-liquefaction systems, akin trends are perceived. 


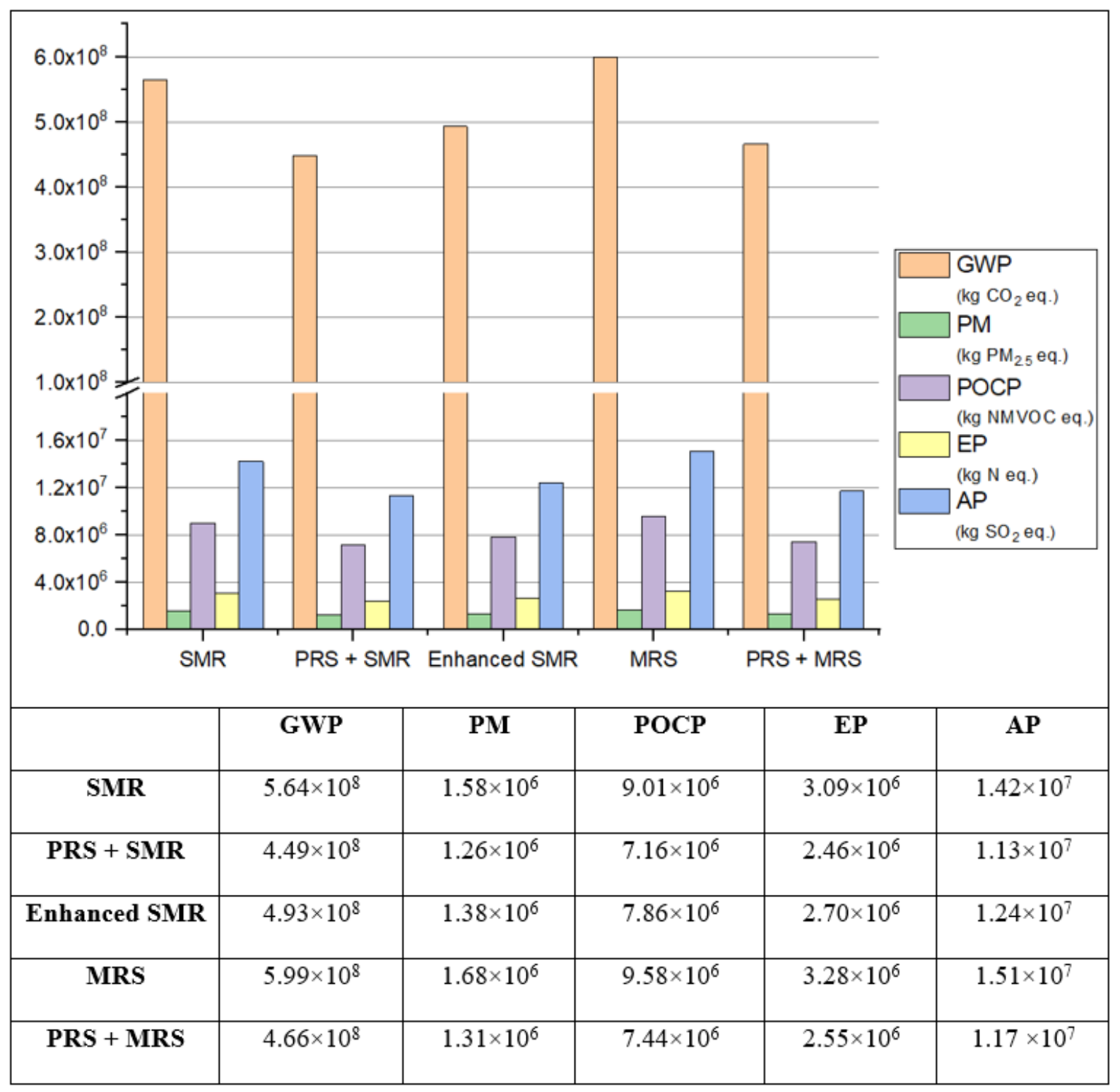

Fig. 7. Five measured emissions from the five re-liquefaction systems

Fig. 8 breaks down the GWP values into individual activity levels. It is seen that the vast majority of GWP stemmed from the use phase. Around $88 \%$ of GWP was ascribed to the operation of the reliquefaction systems. The fuel production phase was proven to be the second greatest contributor, which accounted for about $11 \%$ of the total $\mathrm{CO}_{2}$ eq. Although the rest phases discharged a considerable amount of pollutants associated with GWP, their contributions were relatively negligible as they did not even reach $1 \%$ of the total amount. 


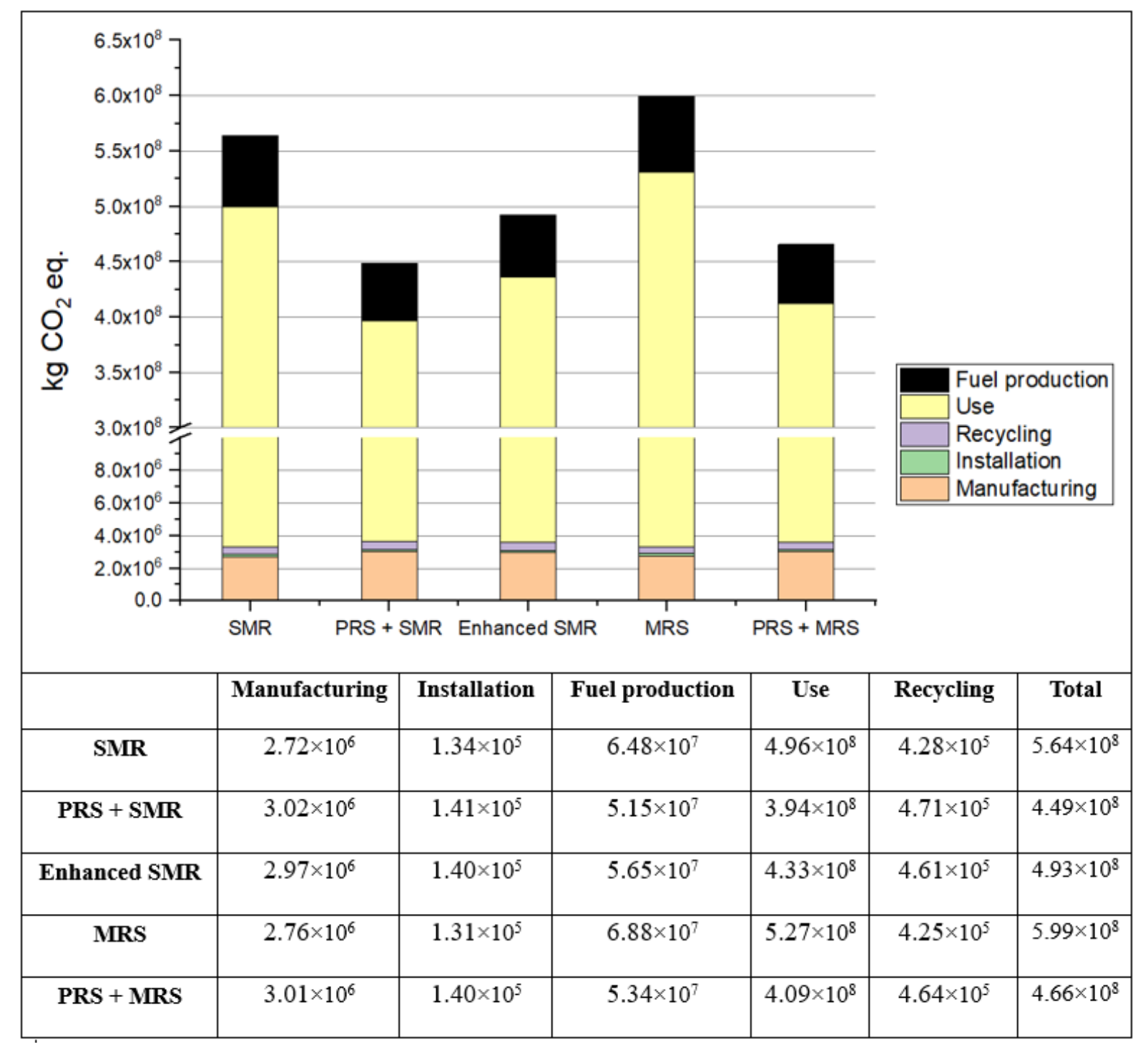

Fig. 8. GWP involved on each phase of the lifecycle

Fig. 9 and Table 11 present the emissions of the other four impact categories except GWP on each stage of the lifecycle. The identical y-axis was placed on all the charts in Fig. 9 for comparison reasons. The bar charts show the cumulative amounts of the four categories over the life cycle stages.

In general, nearly all pollutants in relation to the four potentials were discharged while the systems were re-liquefying BOG onboard LNG carriers. It is noteworthy that the fuel production phase had far less influences on the total emissions of PM, POCP, EP and AP than it did on GWP. Their contributions to the total ranged from $1.5 \%$ to $3 \%$. This implies that these four environmental impacts derived almost totally from the internal combustion processes of onboard generator engines as the electricity generated 
from them was provided to the re-liquefaction systems during their operation. 


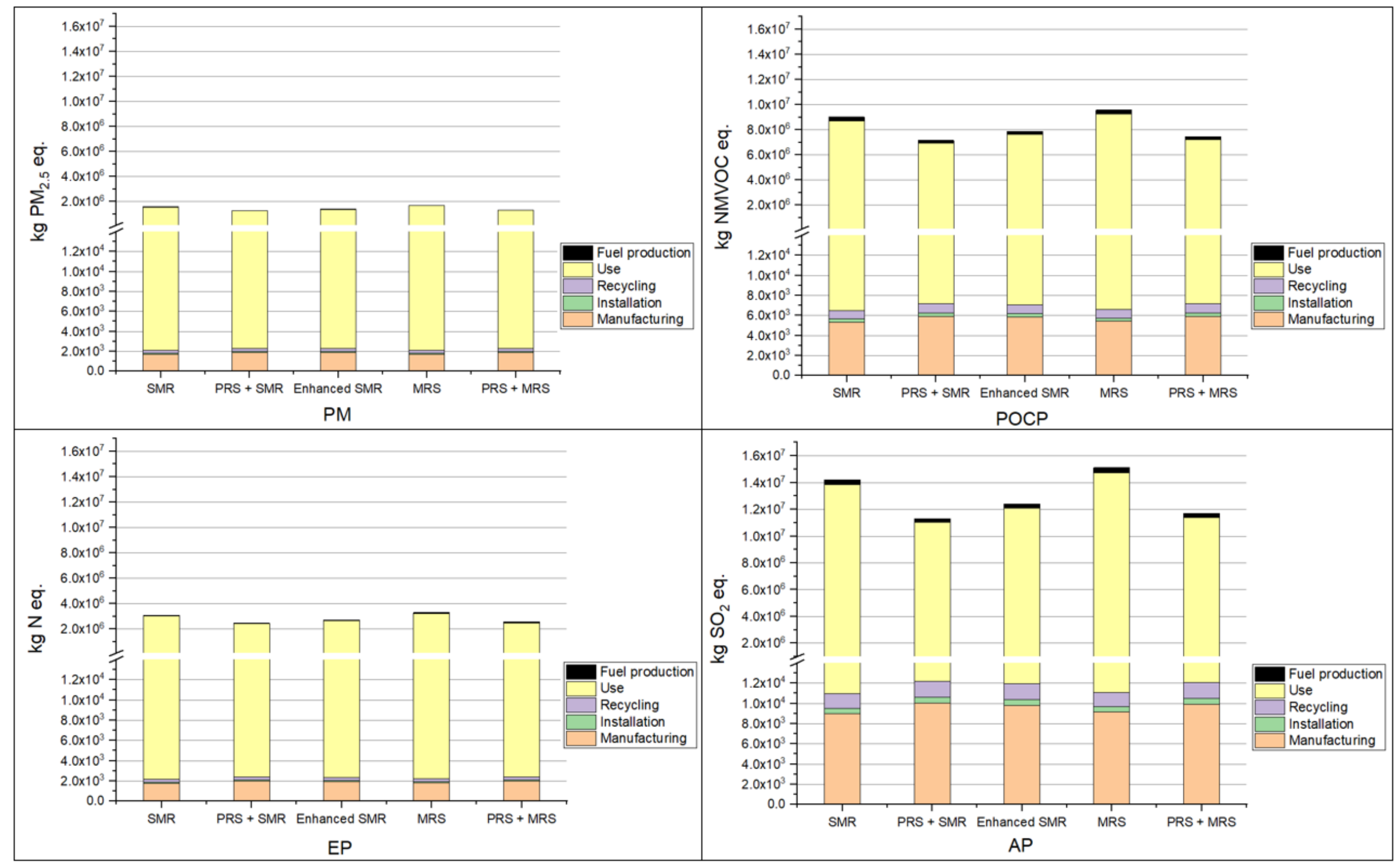

Fig. 9. PM, POCP, EP and AP involved on each life stage of the five re-liquefaction options 
Table 11. PM, POCP, EP and AP on each stage of the lifespan

\begin{tabular}{|c|c|c|c|c|c|c|c|c|}
\hline & Categories & Unit & Manufacturing & Installation & Fuel production & Use & Recycling & Total \\
\hline \multirow{4}{*}{ SMR } & PM & $\mathrm{kg} \mathrm{PM}_{2.5}$ eq. & $1.70 \times 10^{3}$ & $1.07 \times 10^{2}$ & $2.42 \times 10^{4}$ & $1.56 \times 10^{6}$ & $2.73 \times 10^{2}$ & $1.58 \times 10^{6}$ \\
\hline & POCP & kg NMVOC eq. & $5.31 \times 10^{3}$ & $3.32 \times 10^{2}$ & $2.88 \times 10^{5}$ & $8.71 \times 10^{6}$ & $8.50 \times 10^{2}$ & $9.01 \times 10^{6}$ \\
\hline & EP & $\mathrm{kg} \mathrm{N}$ eq. & $1.78 \times 10^{3}$ & $1.11 \times 10^{2}$ & $7.79 \times 10^{4}$ & $3.01 \times 10^{6}$ & $2.84 \times 10^{2}$ & $3.09 \times 10^{6}$ \\
\hline & $\mathrm{AP}$ & $\mathrm{kg} \mathrm{SO}_{2}$ eq. & $8.95 \times 10^{3}$ & $5.60 \times 10^{2}$ & $3.77 \times 10^{5}$ & $1.38 \times 10^{7}$ & $1.43 \times 10^{3}$ & $1.42 \times 10^{7}$ \\
\hline \multirow{4}{*}{ PRS + SMR } & PM & $\mathrm{kg} \mathrm{PM}_{2.5}$ eq. & $1.90 \times 10^{3}$ & $1.13 \times 10^{2}$ & $1.93 \times 10^{4}$ & $1.24 \times 10^{6}$ & $2.99 \times 10^{2}$ & $1.26 \times 10^{6}$ \\
\hline & POCP & kg NMVOC eq. & $5.91 \times 10^{3}$ & $3.52 \times 10^{2}$ & $2.28 \times 10^{5}$ & $6.92 \times 10^{6}$ & $9.32 \times 10^{2}$ & $7.16 \times 10^{6}$ \\
\hline & EP & $\mathrm{kg} \mathrm{N}$ eq. & $1.98 \times 10^{3}$ & $1.18 \times 10^{2}$ & $6.19 \times 10^{4}$ & $2.40 \times 10^{6}$ & $3.12 \times 10^{2}$ & $2.46 \times 10^{6}$ \\
\hline & $\mathrm{AP}$ & $\mathrm{kg} \mathrm{SO}_{2}$ eq. & $1.00 \times 10^{4}$ & $5.93 \times 10^{2}$ & $3.00 \times 10^{5}$ & $1.10 \times 10^{7}$ & $1.57 \times 10^{3}$ & $1.13 \times 10^{7}$ \\
\hline \multirow{4}{*}{$\begin{array}{c}\text { Enhanced } \\
\text { SMR }\end{array}$} & PM & $\mathrm{kg} \mathrm{PM}_{2.5}$ eq. & $1.87 \times 10^{3}$ & $1.12 \times 10^{2}$ & $2.11 \times 10^{4}$ & $1.36 \times 10^{6}$ & $2.93 \times 10^{2}$ & $1.38 \times 10^{6}$ \\
\hline & POCP & kg NMVOC eq. & $5.81 \times 10^{3}$ & $3.47 \times 10^{2}$ & $2.51 \times 10^{5}$ & $7.60 \times 10^{6}$ & $9.12 \times 10^{2}$ & $7.86 \times 10^{6}$ \\
\hline & EP & kg N eq. & $1.94 \times 10^{3}$ & $1.16 \times 10^{2}$ & $6.80 \times 10^{4}$ & $2.63 \times 10^{6}$ & $3.05 \times 10^{2}$ & $2.70 \times 10^{6}$ \\
\hline & $\mathrm{AP}$ & $\mathrm{kg} \mathrm{SO}_{2}$ eq. & $9.82 \times 10^{3}$ & $5.85 \times 10^{2}$ & $3.29 \times 10^{5}$ & $1.21 \times 10^{7}$ & $1.54 \times 10^{3}$ & $1.24 \times 10^{7}$ \\
\hline \multirow{4}{*}{ MRS } & PM & $\mathrm{kg} \mathrm{PM}_{2.5}$ eq. & $1.74 \times 10^{3}$ & $1.05 \times 10^{2}$ & $2.57 \times 10^{4}$ & $1.65 \times 10^{6}$ & $2.71 \times 10^{2}$ & $1.68 \times 10^{6}$ \\
\hline & POCP & kg NMVOC eq. & $5.41 \times 10^{3}$ & $3.26 \times 10^{2}$ & $3.06 \times 10^{5}$ & $9.26 \times 10^{6}$ & $8.44 \times 10^{2}$ & $9.58 \times 10^{6}$ \\
\hline & EP & $\mathrm{kg} \mathrm{N}$ eq. & $1.81 \times 10^{3}$ & $1.09 \times 10^{2}$ & $8.28 \times 10^{4}$ & $3.20 \times 10^{6}$ & $2.82 \times 10^{2}$ & $3.28 \times 10^{6}$ \\
\hline & $\mathrm{AP}$ & $\mathrm{kg} \mathrm{SO}_{2}$ eq. & $9.13 \times 10^{3}$ & $5.49 \times 10^{2}$ & $4.01 \times 10^{5}$ & $1.47 \times 10^{7}$ & $1.42 \times 10^{3}$ & $1.51 \times 10^{7}$ \\
\hline \multirow{4}{*}{ PRS + MRS } & PM & $\mathrm{kg} \mathrm{PM}_{2.5}$ eq. & $1.90 \times 10^{3}$ & $1.12 \times 10^{2}$ & $2.00 \times 10^{4}$ & $1.29 \times 10^{6}$ & $2.95 \times 10^{2}$ & $1.31 \times 10^{6}$ \\
\hline & POCP & kg NMVOC eq. & $5.91 \times 10^{3}$ & $3.47 \times 10^{2}$ & $2.37 \times 10^{5}$ & $7.19 \times 10^{6}$ & $9.18 \times 10^{2}$ & $7.44 \times 10^{6}$ \\
\hline & EP & $\mathrm{kg} \mathrm{N}$ eq. & $1.97 \times 10^{3}$ & $1.16 \times 10^{2}$ & $6.43 \times 10^{4}$ & $2.49 \times 10^{6}$ & $3.07 \times 10^{2}$ & $2.55 \times 10^{6}$ \\
\hline & $\mathrm{AP}$ & $\mathrm{kg} \mathrm{SO}_{2}$ eq. & $9.92 \times 10^{3}$ & $5.85 \times 10^{2}$ & $3.11 \times 10^{5}$ & $1.14 \times 10^{7}$ & $1.55 \times 10^{3}$ & $1.17 \times 10^{7}$ \\
\hline
\end{tabular}


The LCIA results have demonstrated that the PRS will contribute to reducing the adverse environmental impacts overall. To repeat, the PRS-combined systems were confirmed to emit least amount of pollutants across the life cycle phases. Given 25 years of the ship lifespan, the governing factor that causes emissions is associated with all activities in relation to the production and the use of electricity for operating the systems, which guides us much about why the PRSs with high efficiency needs to be used for LNG carriers. Indeed, from the findings, it can be inferred that environmental impacts are heavily relied on the system efficiency.

It should be worthwhile to further identify environmental harms with the life stages other than energy production and system operation (use and fuel production phases). Fig. 10 illustrates how much pollutants were produced from the manufacturing, installation and recycling stages. Whilst a considerable amount of GHG (Greenhouse Gas) was discharged, the emission degrees of the other categories were relatively insignificant. Unlike the total estimated results, the two PRS plants produced more emissions in those stages. This is because they contain not only additional components such as heat exchangers and compressors but also more loop pipes to raise the energy efficiency as much as possible. 


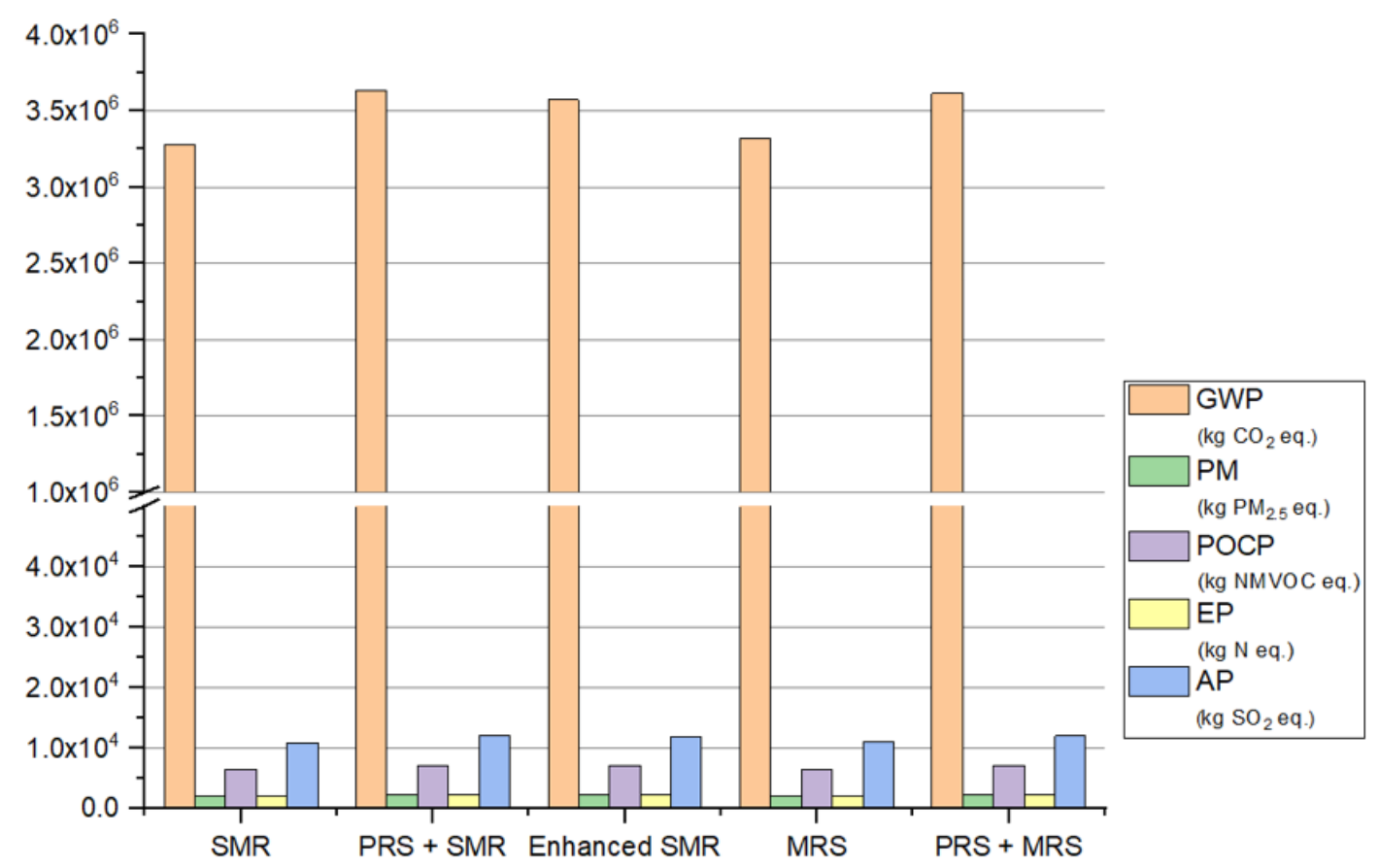

Fig. 10. Emissions from manufacturing, installation and recycling activities

The identified GWP can be traced back to the production and recycling activities of the materials. Fig. 11 shows the material compositions of each system and energy used for manufacturing and recycling the materials within the systems. More than half the systems would be made from stainless steel due to the cryogenic behavior of LNG. Cast iron and cast steel formed approximately $20 \%$ of the systems. Only a small percentage of the systems consisted of Aluminum. It was observed that aluminum and stainless-steel parts had more adverse impacts on nature considering the proportions of them in the systems. 


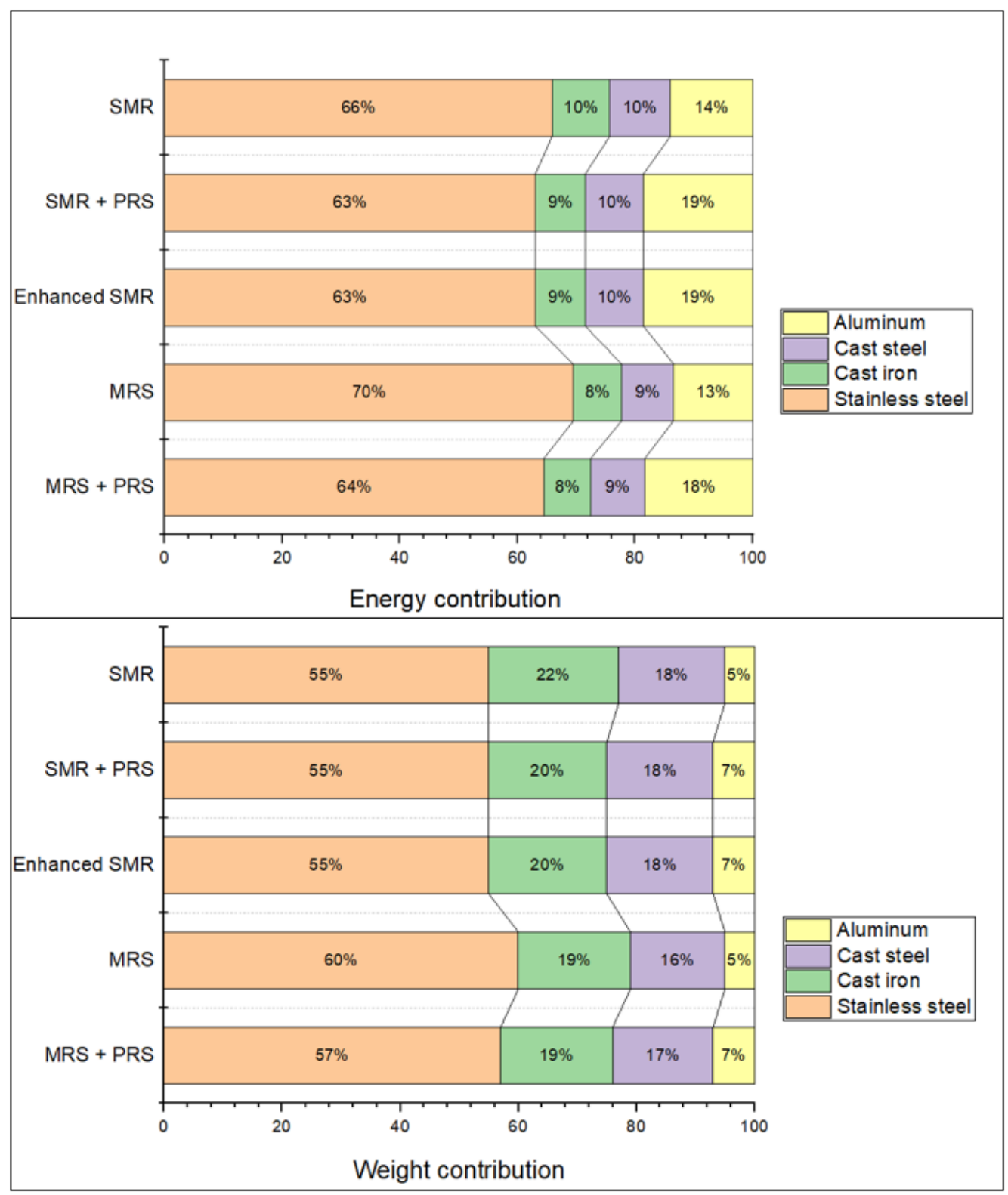

Fig. 11. Identification of environmentally burdensome materials

\subsection{Sensitivity analysis (Results of Interpretation)}

It has been confirmed that whether the system has a high energy efficiency or not is critical in terms of emission levels. Re-liquefaction plants are not likely to operate at their optimal loads at all times due to system worn-out, variation in BOG usage and so forth. Those situations would have an influence on the energy consumption of the proposed systems to a certain degree. A sensitivity analysis considering several possible deviations in electricity consumption was conducted; $20 \%$ less, $10 \%$ less, $10 \%$ more 
and $20 \%$ more electricity consumed by the re-liquefaction systems. Table 12 presents the percentages representing relative ratios to the emissions calculated by the LCIA. Throughout all the four scenarios, the two PRS options were the most environmentally favorable.

Table 12. Sensitivity analysis on electricity consumption

\begin{tabular}{|c|c|c|c|c|c|}
\hline & & & & & \\
\hline & Category & $-20 \%$ & $-10 \%$ & $+10 \%$ & $+20 \%$ \\
\hline & GWP & $79.97 \%$ & $89.90 \%$ & $109.92 \%$ & $119.85 \%$ \\
\hline & PM & $80.41 \%$ & $90.52 \%$ & $110.11 \%$ & $120.23 \%$ \\
\hline SMR & POCP & $80.01 \%$ & $90.01 \%$ & $109.99 \%$ & $119.99 \%$ \\
\hline & EP & $79.95 \%$ & $89.97 \%$ & $110.03 \%$ & $120.05 \%$ \\
\hline & AP & $80.30 \%$ & $90.15 \%$ & $110.56 \%$ & $120.41 \%$ \\
\hline & GWP & $80.16 \%$ & $90.19 \%$ & $110.03 \%$ & $119.84 \%$ \\
\hline & PM & $80.20 \%$ & $89.70 \%$ & $109.51 \%$ & $119.80 \%$ \\
\hline PRS + SMR & POCP & $80.02 \%$ & $90.08 \%$ & $110.06 \%$ & $119.98 \%$ \\
\hline & $\mathrm{EP}$ & $80.10 \%$ & $89.85 \%$ & $109.75 \%$ & $119.90 \%$ \\
\hline & AP & $80.11 \%$ & $90.28 \%$ & $109.72 \%$ & $120.33 \%$ \\
\hline & GWP & $80.10 \%$ & $90.05 \%$ & $109.95 \%$ & $119.90 \%$ \\
\hline & PM & $80.47 \%$ & $89.87 \%$ & $110.13 \%$ & $120.26 \%$ \\
\hline & POCP & $80.02 \%$ & $90.07 \%$ & $110.05 \%$ & $119.98 \%$ \\
\hline & EP & $80.02 \%$ & $90.01 \%$ & $109.99 \%$ & $119.98 \%$ \\
\hline & AP & $80.10 \%$ & $90.33 \%$ & $110.47 \%$ & $120.14 \%$ \\
\hline & GWP & $79.98 \%$ & $89.99 \%$ & $109.84 \%$ & $119.86 \%$ \\
\hline & PM & $80.38 \%$ & $90.49 \%$ & $110.11 \%$ & $120.21 \%$ \\
\hline & POCP & $79.95 \%$ & $89.98 \%$ & $109.71 \%$ & $120.15 \%$ \\
\hline & $\mathrm{EP}$ & $80.20 \%$ & $90.25 \%$ & $110.05 \%$ & $120.11 \%$ \\
\hline
\end{tabular}




\begin{tabular}{|c|c|c|c|c|c|} 
& AP & $80.15 \%$ & $90.07 \%$ & $109.93 \%$ & $120.51 \%$ \\
\hline & GWP & $80.24 \%$ & $90.12 \%$ & $110.09 \%$ & $119.97 \%$ \\
\cline { 2 - 6 } & PM & $80.19 \%$ & $90.09 \%$ & $109.91 \%$ & $119.81 \%$ \\
\cline { 2 - 6 } & POCP & $79.97 \%$ & $89.92 \%$ & $109.95 \%$ & $119.90 \%$ \\
\cline { 2 - 6 } & EP + MRS & $80.02 \%$ & $89.81 \%$ & $109.79 \%$ & $119.98 \%$ \\
\cline { 2 - 6 } & AP & $80.28 \%$ & $90.61 \%$ & $110.25 \%$ & $120.49 \%$ \\
\hline
\end{tabular}

Another sensitivity study was performed concerning the fuel type for onboard power generation since the use phase of the re-liquefaction systems contributed the most to the estimated emissions via the LCIA. MGO and LNG were selected for these analyses. In the case of LNG, the reduction in BOG due to the gas consumption for power generation was not considered. Table 13 displays both rises and declines in emissions compared to the HFO case. The most remarkable finding is that there was more GWP when the auxiliary engines of the case ship were operated on MGO or LNG. As for the MGO case, the increased GWP is derived from the larger $\mathrm{CO}_{2}$ emission factor than that of HFO.

Unlike the case of MGO, the use of LNG resulted in more potential relating to global warming despite the $\mathrm{CO}_{2}$ factor being lower than those of HFO and MGO. To examine the cause of the increment, another simulation was carried out with a different $\mathrm{CH}_{4}$ factor of $2.0 \times 10^{-2}$. The factor was obtained from an LCA study regarding marine fuels (Gilbert et al. (2018). The LNG case 2 with the lower $\mathrm{CH}_{4}$ factor led to a moderate fall in the GWP in comparison to that of HFO. From the results of the LNG case 2, it was reminded that methane slip would be of significance as for the GWP. The reason is that $1 \mathrm{~kg}$ of methane causes far more serious harm to the environment than the same amount of $\mathrm{CO}_{2}$. The relatively higher methane emission factor from IMO might be due to the fact that the study only considered low-pressure dual fuel engines, which are known to involve more methane slip than their high-pressure counterparts.

In the case of the lowered methane slip, there were reductions in all five impact categories. Especially, the emission levels except GWP plunged by a range from 80 to $96 \%$. In spite of the slightly increased GWP, the use of MGO instead of HFO cut significant amounts of PM and AP. Such an improvement is 
achieved by the fact that those two potentials are closely related to the sulphur content of fuels used. The improved POCP and EP were also discovered.

With all the three fuel cases considered, it can be finally concluded that the two re-liquefaction systems incorporating PRSs will contribute the least to the pollution of the environment.

Table 13. Sensitivity analysis on the fuel type for electricity

\begin{tabular}{|c|c|c|c|c|}
\hline & & & Variation & \\
\hline & Category & MGO & LNG (case 1) & LNG (case 2) \\
\hline & GWP & $103.72 \%$ & $112.05 \%$ & $92.73 \%$ \\
\hline & PM & $15.55 \%$ & $4.14 \%$ & $4.14 \%$ \\
\hline SMR & POCP & $88.01 \%$ & $20.39 \%$ & $19.95 \%$ \\
\hline & $\mathrm{EP}$ & $94.50 \%$ & $16.18 \%$ & $16.18 \%$ \\
\hline & $\mathrm{AP}$ & $32.16 \%$ & $6.11 \%$ & $6.11 \%$ \\
\hline & GWP & $103.79 \%$ & $112.04 \%$ & $92.87 \%$ \\
\hline & PM & $15.55 \%$ & $4.17 \%$ & $4.17 \%$ \\
\hline PRS + SMR & POCP & $88.12 \%$ & $20.36 \%$ & $19.94 \%$ \\
\hline & EP & $94.31 \%$ & $16.18 \%$ & $16.18 \%$ \\
\hline & $\mathrm{AP}$ & $32.11 \%$ & $6.14 \%$ & $6.14 \%$ \\
\hline & GWP & $103.65 \%$ & $111.98 \%$ & $92.89 \%$ \\
\hline & PM & $15.57 \%$ & $4.16 \%$ & $4.16 \%$ \\
\hline Enhanced & POCP & $88.04 \%$ & $20.33 \%$ & $19.94 \%$ \\
\hline & EP & $94.08 \%$ & $16.18 \%$ & $16.18 \%$ \\
\hline & $\mathrm{AP}$ & $32.16 \%$ & $6.13 \%$ & $6.13 \%$ \\
\hline & GWP & $103.67 \%$ & $112.01 \%$ & $92.83 \%$ \\
\hline MRS & PM & $15.52 \%$ & $4.13 \%$ & $4.13 \%$ \\
\hline
\end{tabular}




\begin{tabular}{|c|c|c|c|c|} 
& POCP & $87.99 \%$ & $20.33 \%$ & $19.91 \%$ \\
\cline { 2 - 5 } & EP & $94.52 \%$ & $16.21 \%$ & $16.21 \%$ \\
\cline { 2 - 5 } & AP & $32.17 \%$ & $6.11 \%$ & $6.11 \%$ \\
\hline \multirow{3}{*}{ PRS + MRS } & GWP & $103.87 \%$ & $112.24 \%$ & $92.91 \%$ \\
\cline { 2 - 5 } & PM & $15.49 \%$ & $4.16 \%$ & $4.16 \%$ \\
\cline { 2 - 5 } & POCP & $88.03 \%$ & $20.40 \%$ & $19.86 \%$ \\
\cline { 2 - 5 } & AP & $94.51 \%$ & $16.20 \%$ & $6.15 \%$ \\
\cline { 2 - 5 } & AP & $32.21 \%$ & $6.15 \%$ & $16.20 \%$ \\
\hline
\end{tabular}

How varied BORs can affect the environmental performance of the considered systems is presented in Table 14. The changed rates were positively correlated with the five emissions in both optimistic and conservative scenarios. However, it was proven that the two considered PRS options would be the least harmful in all five environmental potentials. Indeed, all the five re-liquefaction systems showed similar trends of rise/drop in emissions according to the altered BORs.

Table 14. Sensitivity analysis on different BORs

\begin{tabular}{|c|c|c|c|}
\hline \multirow{2}{*}{} & & \multicolumn{2}{c|}{ Variation } \\
\hline \multirow{3}{*}{ SMR } & Category & $\mathbf{0 . 0 5 \%} / \mathbf{d a y}$ & $\mathbf{0 . 1 \%} / \mathbf{d a y}$ \\
\cline { 2 - 4 } & GWP & $66.51 \%$ & $132.61 \%$ \\
\cline { 2 - 4 } & PM & $66.50 \%$ & $132.87 \%$ \\
\cline { 2 - 4 } & POCP & $66.47 \%$ & $133.31 \%$ \\
\cline { 2 - 4 } & EP & $66.37 \%$ & $132.99 \%$ \\
\hline \multirow{3}{*}{ PRS + SMR } & AP & $66.65 \%$ & $133.07 \%$ \\
\cline { 2 - 4 } & GWP & $66.79 \%$ & $132.77 \%$ \\
\hline
\end{tabular}




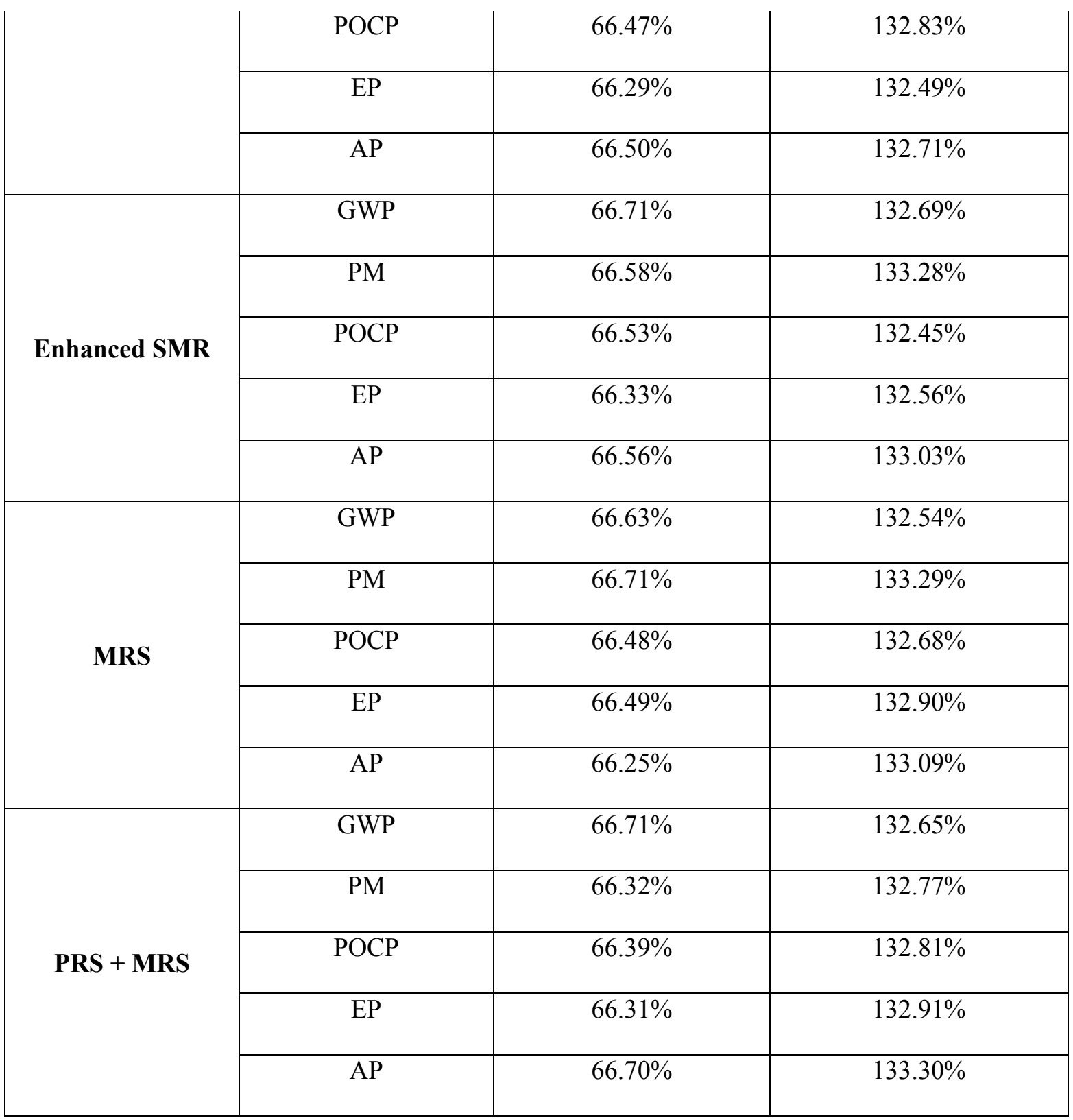

Table 15 explicitly indicates the higher efficient heat exchangers, the less pollutants. What is noticeable is that the SMR and the MRS were affected less due to the heat exchange performance compared with the other options. The reason is that the three re-liquefaction options utilize BOG's cold energy by placing more heat exchangers or precooling in a larger main heat exchanger. Although the gap between the PRS introduced options and the rest ones was lessened slightly owing to the reduced heat transfer rates, the PRS + SMR still emitted the least pollutants, which were approximately $23 \%$ less than those of the MRS. 
Table 15 . Sensitivity analysis on the varied efficiencies of heat exchangers

\begin{tabular}{|c|c|c|c|c|}
\hline & & & Variation & \\
\hline & Category & $70 \%$ & $80 \%$ & $90 \%$ \\
\hline & GWP & $127.82 \%$ & $118.61 \%$ & $109.39 \%$ \\
\hline & PM & $128.44 \%$ & $118.96 \%$ & $109.48 \%$ \\
\hline SMP & POCP & $127.76 \%$ & $118.88 \%$ & $109.55 \%$ \\
\hline & EP & $128.14 \%$ & $118.76 \%$ & $109.70 \%$ \\
\hline & AP & $128.15 \%$ & $119.00 \%$ & $109.85 \%$ \\
\hline & GWP & $130.54 \%$ & $120.51 \%$ & $110.48 \%$ \\
\hline & PM & $130.10 \%$ & $120.60 \%$ & $110.30 \%$ \\
\hline PRS + SMR & POCP & $130.60 \%$ & $120.54 \%$ & $110.48 \%$ \\
\hline & $\mathrm{EP}$ & $130.46 \%$ & $120.31 \%$ & $110.15 \%$ \\
\hline & AP & $130.94 \%$ & $120.33 \%$ & $110.61 \%$ \\
\hline & GWP & $130.25 \%$ & $120.30 \%$ & $110.35 \%$ \\
\hline & PM & $130.38 \%$ & $120.26 \%$ & $110.85 \%$ \\
\hline Enhanced & POCP & $129.91 \%$ & $120.49 \%$ & $110.44 \%$ \\
\hline & $\mathrm{EP}$ & $130.34 \%$ & $120.35 \%$ & $110.36 \%$ \\
\hline & AP & $130.62 \%$ & $120.95 \%$ & $110.47 \%$ \\
\hline & GWP & $127.36 \%$ & $118.19 \%$ & $109.01 \%$ \\
\hline & $\mathrm{PM}$ & $127.94 \%$ & $118.43 \%$ & $109.51 \%$ \\
\hline MRS & POCP & $127.46 \%$ & $118.06 \%$ & $108.67 \%$ \\
\hline & $\mathrm{EP}$ & $127.73 \%$ & $118.59 \%$ & $109.14 \%$ \\
\hline & AP & $127.79 \%$ & $118.53 \%$ & $109.26 \%$ \\
\hline PRS + MRS & GWP & $130.28 \%$ & $120.40 \%$ & $110.31 \%$ \\
\hline
\end{tabular}




\begin{tabular}{|c|c|c|c|c|}
\hline & PM & $129.72 \%$ & $119.81 \%$ & $109.91 \%$ \\
\cline { 2 - 5 } & POCP & $130.25 \%$ & $120.30 \%$ & $110.22 \%$ \\
\cline { 2 - 5 } & EP & $130.56 \%$ & $120.37 \%$ & $110.19 \%$ \\
\cline { 2 - 5 } & AP & $130.74 \%$ & $120.49 \%$ & $111.10 \%$ \\
\hline
\end{tabular}

\section{Discussions}

It is necessary to take a way back to the fundamental question posed in Introduction. Research findings are believed to be able to offer an answer-or at least to give an insight into seeking a direction to find the answer-in two folds: industrial applications and implications for theory and practice.

\subsection{Industrial applications}

The LCIA results unveiled that almost all pollutants concerning the five adverse potentials were attributable to the use stage of the re-liquefaction systems, which would be well agreed with a paper which examined emissions during the lifecycle of yachts (Cucinotta et al.,2016). The scope of the analysis seems to be a bit different from that of a marine system. However, the operation of marine engine systems has been identified as the most dominating stage through most past LCA studies as those engines burn an enormous amount of fuels during their lifetime. To make things worse, HFO, the most common marine fuel, is a low-quality oil produced from refinery processes, implying that it can contain harmful substances such as sulphur.

The oil product is also supplied to marine auxiliary engines to generate electricity onboard ships. In other words, LNG re-liquefaction systems consume the HFO in an indirect way during their operation. The research findings suggest three ways to lower emissions released from the systems. First, reliquefaction systems with high energy efficiency is always desirable. In short, the PRS-combined systems could be the best solution. Second, the efficiency of auxiliary engines could be improved or 
optimized considering exact ranges of power use onboard a particular ship. Last, the onboard electricity might be produced by a cleaner fuel source such as LNG, ammonia and hydrogen. However, the emissions from the upstream processes of alternative fuels should be carefully examined since it is also possible that more energy is embodied on the production of alternative fuels compared to traditional oil products.

Another finding was that the use of aluminum and stainless steel can cause harm to nature while it is produced and recycled. In a similar context, Tuan and Wei (2018) emphasized that a significant amount of energy was consumed during material production. In respect to aluminum, about 10 times more energy is spent on the manufacture of aluminum products than cast iron ones according to an LCA reference book (Ashby, 2012). It can be recommended that the use of aluminum for re-liquefaction plants should be lowered if other types of materials could replace it. However, aluminum is mainly used for the heat exchangers of re-liquefaction systems owing to its good heat transfer characteristics. It must be difficult to choose an alternative material, since it can directly affect the system efficiency, the most crucial contributor to emissions as described earlier. As for stainless steel, the use of it may be reduced by optimal pipe paths and more precise process simulations since it composes most of cryogenic parts. With the upward demand for LNG carriers, this research has confirmed that the application of the PRS will make a robust contribution to reducing emissions in the LNG shipping field. When it comes to global LNG supply chain, the emissions attributed to onboard re-liquefaction systems belong to the shipping category. According to Mallapragada et al. (2018), this stage emitted the most pollutants if the power production phase as an end-user was excluded in the case of LNG exports from the USA to diverse probable importing nations in Europe, Asia and South America. This research assumed that BOG was re-liquefied by onboard systems. However, most of the studies which investigated environmental potentials of the LNG supply chain did not consider various re-liquefaction systems. Given that those systems are one of the greatest power consumers onboard LNG carriers, implementing the PRS options on a large number of LNG trading tankers may be a noticeable contribution to cutting emissions from the supply chain by sea in conjunction with optimal navigation routes and more efficient 
marine engines.

This study also offers an inspiration regarding the offshore units such as FLNG (Floating Liquefied Natural Gas) and FSRU (Floating Storage Regasification Unit), where similar LNG re-liquefaction systems are operated on a much larger scale. Therefore, it can be further inferred that a proper design and use of LNG re-liquefaction systems in the offshore units will lead to more environmental benefits at a larger level than the marine vessels.

The environmental benefits of the PRS can be further extended to other sorts of liquefied gas carriers although each type of ship deals with a different liquid form of gas such as LPG (Liquified Petroleum Gas), ethane, ammonia, hydrogen and so on. The PRS system has to be modified depending on the characteristics of the gas to be treated including its boiling point. Even if the PRS cannot be designed in the same way as those of LNG carriers, this research still delivers insights into how ecologically beneficial it would be to exploit the cold energy stemmed directly from BOG in re-liquefaction processes.

Lastly, research findings from this LCA will help decision makers obtain better information when they select LNG re-liquefaction systems. This study can also encourage designers, manufacturers and operators to improve their products by observing emissions at different life cycle stages.

\subsection{Implications for theory and practice}

IMO and local maritime authorities, which have agreed with the reduction of GHG by half of 2008 level by 2050 , are presently striving to find a proper measurement to assess the emission levels (IMO, 2018). LCA is highly believed as a perfect fit for this need due to the fact that the method is even more comprehensive, compared to the conventional environmental assessment approaches focusing primarily on GHG. Most experts in the marine industry have claimed that the improvement of system efficiency alone may not be able to achieve GHG 2050 goal. Instead, LCA can guide us all directions to cut diverse harmful potentials attributable to maritime activities. 
This LCA research has evidently proven that the integration of the PRS either with the SMR or the MRS could significantly contribute to curbing emissions. The methodology introduced for this study can have useful implications for the marine industry with providing an LCA idea. Not only marine systems but also a wide range of machinery or land-based plants are bound to release far more emissions on their operational phases compared to other stages of their life cycles, which means that calculating emissions during operation is essential in assessing environmental potentials of the systems. This LCA has adopted HYSYS analyses to estimate the efficiencies of the re-liquefaction options, which can be regarded as adding an effective tool to existing theories regarding environmental assessment.

The developed LCA approach can be employed by practitioners in a myriad of fields. Especially global corporations have been exploring ways to accomplish more sustainable and greener production. There is often scarce data available in regard to products manufactured by commercial companies. This tool will help experts establish their future schemes for cleaner industrial activities.

The novelty of this study may be to take a different path by evaluating the excellence of the PRS system from a holistic environmental impact perspective as most of the previous studies aimed to investigate the operating performance of LNG re-liquefaction systems in terms of efficiency. Another notable point of this research is that an LCA study was combined with HYSYS process simulations, which estimated the power consumption of the five considered options. As LCA is still underused in the marine industry, this research can contribute to expanding the usage of LCA in this sector as a standard environmental measurement tool.

\section{Conclusions}

The findings of this LCA study can be summarized as follows.

- The PRS-combined LNG re-liquefaction systems-the PRS + SMR and the PRS + MRSwere found to excel in the energy efficiency and environmental performance over the conventional systems such as the SMR, the MRS and the Enhanced SMR. 
- As the most optimal solution, when the PRS + SMR is applied to a 174K LNG carrier over 25 years, it was estimated to produce $4.49 \times 10^{8} \mathrm{~kg} \mathrm{CO}_{2}$ eq., $1.25 \times 10^{6} \mathrm{~kg} \mathrm{PM} 2.5$ eq., $7.16 \times 10^{6} \mathrm{~kg}$ NMVOC eq., $2.46 \times 10^{6} \mathrm{~kg} \mathrm{~N}$ eq. and $1.13 \times 10^{7} \mathrm{~kg} \mathrm{SO}_{2}$ eq. in its lifetime, which were roughly up to $25 \%$ less than the conventional systems.

- Chemical process simulations incorporated with the LCA were found helpful to quantify the amounts of varied pollutants during the operation of the re-liquefaction systems. This fusion method may be employed in other industrial sectors to accomplish better assessment.

LNG has been in the spotlight in many sectors which seek strategies to curtail harm to the environment. This fuel has been proven to discharge far less emissions during its combustion in comparison to conventional fossil fuels by a variety of research; however, it is also vital to lower environmentally adverse potentials attributable to all the previous stages starting from its birth to achieve truly cleaner industrial activities. In this respect, this LCA research is expected to contribute to reduction in emissions from LNG shipping, which is part of LNG supply chain paths by encouraging concerned decision makers to introduce eco-friendly PRS re-liquefaction systems onboard LNG carriers. Considering a rising trend in international LNG usage, the introduction of the PRS systems instead of traditional options may be a noteworthy addition to the efforts to lower emissions generated from the transportation of LNG by sea.

In practice, another PRS option might be better suited for LNG trading tankers although this research has demonstrated that the PRS + SMR was the environmentally most favorable system with a full reliquefaction capacity. The reason is that there would be some challenges encountered with the PRS + SMR due to the difficulty of the management of single mixed refrigerants under the sea-going condition, which brings about high operational and maintenance costs. Given this, the PRS + MRS, which recorded second least emissions, could be a good alternative with good operability and almost equivalently excellent environmental performance. The single PRS or the enhanced PRS can also be considered to be implemented depending on the size of LNG carriers, navigation routes, management strategies of each company and so on. 
There is still some work to be done to develop this research further as below.

- Maintenance and transport phases of LNG re-liquefaction modules can be taken into account to cover their entire life cycles even if the impacts may be less than the other considered stages.

- More diverse LCA categories may be explored to discuss other environmental effects caused by LNG re-liquefaction onboard LNG carriers.

- The results should be drawn by more case LNG trading tankers whose cargo capacities differ with various route scenarios to obtain more objective and reliable findings.

- Assessment on costs or risks involved in employing LNG re-liquefaction systems can help select a superior option from different perspectives.

\section{Acknowledgements}

The authors would like to express their gratitude to Daewoo Shipbuilding and Marine Engineering LTD, and Hyundai LNG Shipping LTD for offering valuable data and information which have made a great use for this research. 


\section{References}

Alkaner, S., Zhou, P., 2006. A comparative study on life cycle analysis of molten carbon fuel cells and diesel engines for marine application. Journal of power sources 158(1), 188-199.

Ashby, M.F., 2012. Materials and the environment: eco-informed material choice. Elsevier.

Basurko, O.C., Mesbahi, E., 2014. Methodology for the sustainability assessment of marine technologies. Journal of cleaner production 68, 155-164.

Bengtsson, S., Andersson, K., Fridell, E., 2011. A comparative life cycle assessment of marine fuels: liquefied natural gas and three other fossil fuels. Proceedings of the Institution of Mechanical Engineers, Part M: Journal of Engineering for the Maritime Environment 225(2), 97-110.

BP, 2019. BP Statistical Review of World Energy (68th edition).

Brynolf, S., Fridell, E., Andersson, K., 2014. Environmental assessment of marine fuels: liquefied natural gas, liquefied biogas, methanol and bio-methanol. Journal of cleaner production 74, 86-95.

Choi, B.C., Park, K.-H., Doh, D.-H., 2018. Impacts of initial temperature and cylindrical obstacles on the dispersing flammable limits of accidental methane releases in an LNG bunkering terminal. Journal of hazardous materials 355, 104-110.

Choi, J., 2018. Development of partial liquefaction system for liquefied natural gas carrier application using exergy analysis. International Journal of Naval Architecture

Ocean Engineering 10(5), 609-616.

Christopher, E.S., 2019. Qatar Petroleum tenders for 60-100 new LNG carriers. https://www.ogj.com/articles/2019/04/qatar-petroleum-tenders-for-60-100-new-lng-carriers.html.

Cucinotta, F., Guglielmino, E., Sfravara, F., 2017. Life cycle assessment in yacht industry: A case study of comparison between hand lay-up and vacuum infusion. Journal of cleaner production 142, 38223833.

Dixit, M.K., Fernández-Solís, J.L., Lavy, S., Culp, C.H., 2012. Need for an embodied energy measurement protocol for buildings: A review paper. J Renewable sustainable energy reviews 16(6), 3730-3743.

Dobrota, Đ., Lalić, B., Komar, I., 2013. Problem of boil-off in LNG supply chain. J Transactions on maritime science 2(02), 91-100.

Favi, C., Campi, F., Germani, M., Manieri, S., 2018. Using design information to create a data framework and tool for life cycle analysis of complex maritime vessels. Journal of Cleaner Production 192, 887-905.

Gerdsmeyer, K., Isalski, W., 2005. On-board reliquefaction for lng ships, Proc. of the Gas Processors Association Europe Conference, London, May 2005.

Gilbert, P., Walsh, C., Traut, M., Kesieme, U., Pazouki, K., Murphy, A., 2018. Assessment of full lifecycle air emissions of alternative shipping fuels. Journal of cleaner production 172, 855-866.

Gómez, J.R., Gómez, M.R., Garcia, R.F., Catoira, A.D.M., 2013. On board LNG reliquefaction technology: a comparative study. J Polish maritime research 21(1), 77-88.

Gourdon, K., Steidl, C., 2019. Global value chains and the shipbuilding industry.

Hamid, M.K.A., 2007. HYSYS: An Introduction to Chemical Engineering Simulation. J Apostila de Hamid.

Hua, J., Cheng, C.-W., Hwang, D.-S., 2019. Total life cycle emissions of post-Panamax containerships 
powered by conventional fuel or natural gas. J Journal of the Air Waste Management Association 69(2), 131-144.

Huan, T., Hongjun, F., Wei, L., Guoqiang, Z., 2019. Options and evaluations on propulsion systems of LNG carriers, Propulsion Systems. IntechOpen.

Hwang, S., Jeong, B., Jung, K., Kim, M., Zhou, P., 2019. Life cycle assessment of LNG fueled vessel in domestic services. Journal of Marine Science Engineering 7(10), 359.

Iannaccone, T., Landucci, G., Tugnoli, A., Salzano, E., Cozzani, V., 2020. Sustainability of cruise ship fuel systems: Comparison among LNG and diesel technologies. Journal of Cleaner Production, 121069.

IMO, 2014. Third IMO GHG Study 2014. https://glomeep.imo.org/wpcontent/uploads/2016/06/GHG3-Executive-Summary-and-Report_web.pdf.

IMO, 2018. RESOLUTION MEPC.304(72) - INITIAL IMO STRATEGY ON REDUCTION OF GHG EMISSIONS FROM SHIPS

ISO, E., 2006. Environmental Management $\square$ Life Cycle Assessment $\square$ Principles and Framework (ISO 14040: 2006). The International Organization for Standardization Geneva,, Switzerland.

Jeong, B., Jang, H., Zhou, P., Lee, J.-u., 2019. Investigation on marine LNG propulsion systems for LNG carriers through an enhanced hybrid decision making model. Journal of Cleaner Production 230, 98-115.

Jeong, B., Wang, H., Oguz, E., Zhou, P., 2018. An effective framework for life cycle and cost assessment for marine vessels aiming to select optimal propulsion systems. Journal of Cleaner Production 187, 111130.

Johnsen, T., Fet, A.J.O., DNV, HiÅ, 1999. Screening life cycle assessment of M/V color festival.

Kim, D., Hwang, C., Gundersen, T., Lim, Y., 2019. Process design and economic optimization of boiloff-gas re-liquefaction systems for LNG carriers. J Energy 173, 1119-1129.

Kjeld, A., Rene, S.L., 2009. New Optimization of ME-GI Dual Fuel Engines for LNG Carriers and Marine Vessels in General. J マリンエンジニアリング 44(6), 876-887.

Lee, S.H., 2015. in: Daewoo Shipbuilding and Marine Engineering Co., L. (Ed.) Test System and Method of Partial Reliquefaction Process Apparatus.

Ling-Chin, J., Roskilly, A.P., 2016. A comparative life cycle assessment of marine power systems. Energy Conversion Management 127, 477-493.

Ma, H., Steernberg, K., Riera-Palou, X., Tait, N., 2012. Well-to-wake energy and greenhouse gas analysis of SOX abatement options for the marine industry. J Transportation Research Part D: Transport Environmental Research, Engineering and Management 17(4), 301-308.

Mallapragada, D.S., Reyes-Bastida, E., Roberto, F., McElroy, E.M., Veskovic, D., Laurenzi, I.J., 2018. Life cycle greenhouse gas emissions and freshwater consumption of liquefied Marcellus shale gas used for international power generation. Journal of Cleaner Production 205, 672-680.

MAN, 2020. Marine engine programme. https://marine.man-es.com/docs/defaultsource/shopwaredocuments/marine-engine-programme-2020.pdf?sfvrsn=2f9fd695_23.

Melaaen, E., 2013. Fuel gas handling system and bog reliquefaction for lng carrier - Tivo stroke debut of dual fuel engine. Wartsila.

Nekså, P., Brendeng, E., Drescher, M., Norberg, B., 2010. Development and analysis of a natural gas reliquefaction plant for small gas carriers. J Journal of Natural Gas Science Engineering 2(2-3), 143149.

Nian, V., Yuan, J., 2017. A method for analysis of maritime transportation systems in the life cycle approach-The oil tanker example. Applied energy 206, 1579-1589. 
Nie, Y., Zhang, S., Liu, R.E., Roda-Stuart, D.J., Ravikumar, A.P., Bradley, A., Masnadi, M.S., Brandt, A.R., Bergerson, J., Bi, X.T., 2020. Greenhouse-gas emissions of Canadian liquefied natural gas for use in China: Comparison and synthesis of three independent life cycle assessments. Journal of Cleaner Production, 120701.

PE, 2018. GaBi 4 software-system and databases for life cycle engineering

copyright, TM. Stuttgart, Echterdingen; <http://www.gabi-

software.com>.

Pizzol, M., 2019. Deterministic and stochastic carbon footprint of intermodal ferry and truck freight transport across Scandinavian routes. Journal of Cleaner Production 224, 626-636.

Rahman, S.M., Handler, R.M., Mayer, A.L., 2016. Life cycle assessment of steel in the ship recycling industry in Bangladesh. Journal of Cleaner Production 135, 963-971.

Sen, B., Ercan, T., Tatari, O., 2017. Does a battery-electric truck make a difference?-Life cycle emissions, costs, and externality analysis of alternative fuel-powered Class 8 heavy-duty trucks in the United States. Journal of cleaner production 141, 110-121.

Shi, J., Li, T., Peng, S., Liu, Z., Zhang, H., Jiang, Q., 2015. Comparative Life Cycle Assessment of remanufactured liquefied natural gas and diesel engines in China. Journal of Cleaner Production 101, 129-136.

Sinha, R., Nik, W.M.N.W., 2012. Investigation of propulsion system for large LNG ships, IOP Conference Series: Materials Science and Engineering. IOP Publishing, p. 012004.

Speirs, J., Balcombe, P., Blomerus, P., Stettler, M., Brandon, N., Hawkes, A., 2019. Can natural gas reduce emissions from transport. Heavy goods vehicles

shipping.

Strazza, C., Del Borghi, A., Costamagna, P., Traverso, A., Santin, M., 2010. Comparative LCA of methanol-fuelled SOFCs as auxiliary power systems on-board ships. J Applied Energy 87(5), 16701678.

Tuan, D.D., Wei, C., 2019. Cradle-to-gate life cycle assessment of ships: A case study of Panamax bulk carrier. J Proceedings of the Institution of Mechanical Engineers, Part M: Journal of Engineering for the Maritime Environment 233(2), 670-683.

Vandebroek, L., Berghmans, J., 2012. Safety Aspects of the use of LNG for Marine Propulsion. Procedia engineering 45, 21-26.

Venkatesh, A., Jaramillo, P., Griffin, W.M., Matthews, H.S.J.E.s., technology, 2011. Uncertainty in life cycle greenhouse gas emissions from United States natural gas end-uses and its effects on policy. 45(19), 8182-8189.

Wang, H., Oguz, E., Jeong, B., Zhou, P., 2019. Life cycle and economic assessment of a solar panel array applied to a short route ferry. Journal of Cleaner Production 219, 471-484.

Wang, H., Zhou, P., Liang, Y., Jeong, B., Mesbahi, A., 2020. Optimization of tugboat propulsion system configurations: a holistic life cycle assessment case study. Journal of Cleaner Production, 120903.

WinGD, 2015. Wärtsilä low-speed low-pressure dual-fuel engines - the industry standard. https://www.motorship.com/_data/assets/pdf_file/0029/619229/X-DF-engines-brochure.pdf.

Yuan, X., Zhang, B., Liang, R., Wang, R., Sun, Y., 2020. Environmental Impact of the Natural Gas Liquefaction Process: An Example from China. J Applied Sciences 10(5), 1701.

Yun, S.-K., 2016. Characteristics of boil-off-gas partial re-liquefaction systems in LNG ships. J Journal 
of the Korean Society of Marine Engineering 40(3), 174-179.

Zhang, Y., Jiang, H., Li, J., Shao, S., Hou, H., Qi, Y., Zhang, S., 2018. Life cycle assessment and optimization analysis of different LNG usage scenarios. J The International Journal of Life Cycle Assessment 23(6), 1218-1227. 